Seeing Me, Seeing You

Testing Competing Accounts of Assumed Similarity in Personality Judgments

Thielmann, Isabel; Hilbig, Benjamin E.; Zettler, Ingo

Published in:

Journal of Personality and Social Psychology

DOI:

10.1037/pspp0000222

Publication date:

2020

Document version

Peer reviewed version

Citation for published version (APA):

Thielmann, I., Hilbig, B. E., \& Zettler, I. (2020). Seeing Me, Seeing You: Testing Competing Accounts of Assumed Similarity in Personality Judgments. Journal of Personality and Social Psychology, 118(1), 172-198. https://doi.org/10.1037/pspp0000222 
This work is scheduled to appear in

Journal of Personality and Social Psychology

(C) 2020 American Psychological Association

This manuscript may not exactly replicate the final version published in the journal. It is not the copy of record.

Reference:

Thielmann, I., Hilbig, B. E., \& Zettler, I. (2020). Seeing me, seeing you: Testing competing accounts of assumed similarity in personality judgments. Journal of Personality and Social Psychology, 118, 172-198. https://doi.org/10.1037/pspp0000222 
Seeing me, seeing you: Testing competing accounts of assumed similarity in personality judgments

\author{
Isabel Thielmann ${ }^{1}$, Benjamin E. Hilbig ${ }^{1}, \&$ Ingo Zettler ${ }^{2}$ \\ ${ }^{1}$ University of Koblenz-Landau \\ ${ }^{2}$ University of Copenhagen
}

Please address correspondence to:

Isabel Thielmann, Department of Psychology, University of Koblenz-Landau,

Fortstraße 7, 76829 Landau, Germany; E-Mail: thielmann@uni-landau.de

Note on additional materials:

Additional materials (including the instructions and materials used in the studies as well as the data, complementary analyses, and pre-registrations) are available online at the Open Science Framework (OSF) and can be accessed via the following link: https://osf.io/hxt7r/. We embrace the values of openness and transparency in science (Schönbrodt, Maier, Heene, \& Zehetleitner, 2015). Therefore, we followed the 21-word solution provided by Simmons, Nelson, and Simonsohn (2012). 


\begin{abstract}
A recurrent observation in personality judgments is that individuals' ratings of others' personalities are positively linked to their self-description, and that such "assumed similarity" effects appear to be trait-specific. However, the extent of and explanations for assumed similarity have been addressed only insufficiently. To close this gap, we first provide a metaanalytic summary of evidence on assumed similarity of basic personality traits. More importantly, we then critically test different theoretical accounts of assumed similarity (i.e., lack of information, relevance to personal values, and known/spurious similarity) in nine studies. Specifically, we investigated assumed similarity of the HEXACO personality traits among strangers, using specific experimental tests tackling the different theoretical accounts. Across studies, we consistently found the strongest assumed similarity effects for those traits being most strongly linked to personal values: Honesty-Humility and (albeit somewhat weaker) Openness to Experience. For the remaining traits, no consistent evidence for assumed similarity occurred, even when raters had very limited information about the target person. This contradicts that assumed similarity reflects a lack-of-information effect. In turn, the findings could also neither be accounted for by actual similarity, nor by a shared group membership (i.e., spurious similarity) between rater and target. Overall, our studies support the idea that assumed similarity of basic traits is closely tied to personal values and suggest that this finding is attributable to the high personal relevance of value-related traits. This implies that assumed similarity reflects the assumption that others share basic parts of one's identity, even if these others are complete strangers.
\end{abstract}

Keywords: assumed similarity; personality judgments; personal values; self-relevance; HEXACO 


\section{Seeing me, seeing you: Testing competing accounts of assumed similarity in personality}

\section{judgments}

A wide range of everyday social interactions require individuals to form judgments about other people's characteristics. Indeed, being able to accurately assess what others are like is of vital importance and - from an evolutionary perspective - arguably adaptive because it facilitates predicting others' behaviors (e.g., Cosmides \& Tooby, 1992; Fiske, 1993). Strikingly, research has consistently shown that people's judgments about others' personalities are related to how they describe their own personality. In other words, individuals seem to infer that others are somewhat similar to themselves. Herein, we tackle this phenomenon called assumed similarity (Cronbach, 1955) by summarizing extant evidence on assumed similarity of basic personality traits and, more importantly, by critically testing different theoretical accounts that have been proposed to explain assumed similarity in personality judgments.

\section{Assumed similarity}

Assumed similarity refers to the correspondence between how people describe themselves and others. Specifically, assumed similarity is operationally defined as a (positive) correlation between the self-report of a person A and her observer report of a person B (or vice versa) on some characteristics. Importantly, assumed similarity thereby differs from (a) actual similarity - which is operationally defined as the correlation between person A's selfreport and person B's self-report - and (b) self-observer agreement - which is operationally defined as the correlation between person A's self-report and person B's observer report of person A (or vice versa). That said, assumed similarity has also been frequently operationalized as the relation between a person's self-report and her average observer report on several others in a group, that is, her perceiver effect in terms of the Social Relations Model (SRM; Kenny, 1994; Kenny \& La Voie, 1984; for empirical examples, see e.g., Albright, Kenny, \& Malloy, 1988; De Vries, 2010; Malloy \& Albright, 1990; Paulhus \& 
Reynolds, 1995). In this sense, assumed similarity reflects how prototypical an individual describes herself in relation to a group of others and is thus slightly different from how we operationalize the concept herein, namely, as the level of correspondence between individuals' self-descriptions and their descriptions of other individuals. In any case, however, both operationalizations essentially capture the core of what assumed similarity is about - that is, a certain correspondence between self-descriptions and descriptions of others - and they have, in turn, been shown to converge strongly (De Vries, 2010).

In the literature, several terms other than assumed similarity have been used to refer to a positive relation between self-descriptions and judgments of others. The most commonly known are attributive projection (Holmes, 1968; Sherwood, 1981), self-based heuristic (Ready, Clark, Watson, \& Westerhouse, 2000), false consensus effect (Marks \& Miller, 1987; Ross, Greene, \& House, 1977), and social projection (Krueger, 2007). Of note, all these terms imply specific mechanisms or underlying cognitive processes (Hoch, 1987), as does the term "assumed similarity" which essentially implies that individuals are assuming something. In what follows, however, we will use the term assumed similarity purely as operationally defined, that is, as the positive relation between a person's self-description and her judgment of another on certain personality characteristics, without making strong claims about the underlying (cognitive) processes involved.

\section{Empirical evidence on assumed similarity}

Given the vital importance of personality judgments for everyday social interactions, it is unsurprising that assumed similarity has gained considerable attention in prior research and has been studied for diverse characteristics such as attitudes (e.g., Holtz, 1997; Paunonen \& Kam, 2014), (trait) affectivity ${ }^{1}$ (e.g., Beer, Watson, \& McDade-Montez, 2013; Papp, Kouros,

\footnotetext{
${ }^{1}$ Note that prior research on assumed similarity of (trait) affectivity has primarily relied on (versions of) the Positive and Negative Affect Schedule (PANAS; Watson \& Clark, 1994; Watson, Clark, \& Tellegen, 1988). Given that the PANAS does not contain any reversed-keyed items, corresponding assumed similarity correlations may be inflated by individual differences in response elevation.
} 
\& Cummings, 2010; Watson, Hubbard, \& Wiese, 2000; Weller \& Watson, 2009), communication styles (e.g., Mathison, 1988), and end-of-life decision making (e.g., McDadeMontez, Watson, \& Beer, 2013). However, most research in the context of personality judgments has focused on assumed similarity of broad personality traits as conceptualized in models of basic personality structure, most prominently the Five-Factor Model (FFM; Costa \& McCrae, 1992; McCrae \& Costa, 1985) and the HEXACO Model of Personality (Ashton \& Lee, 2007; Ashton, Lee, \& De Vries, 2014; Ashton et al., 2004). Herein, we likewise focus on assumed similarity in basic personality traits, and Table 1 provides a meta-analytic overview of corresponding evidence on the FFM and the HEXACO dimensions. ${ }^{2}$

As Table 1 reveals, a key finding is that there is a moderate degree of assumed similarity in judgments of basic personality traits. More strikingly, however, the degree of assumed similarity differs across traits. That is, self-reports are only linked to observer reports about others on some, but not on all traits. Among the FFM dimensions (i.e., Neuroticism, Extraversion, Agreeableness, Conscientiousness, and Openness), it has been concluded that "the strongest effects are generally observed for agreeableness" (Wood, Harms, \& Vazire, 2010, p. 176; for similar conclusions, see Kenny, 1994; Leikas, Lönnqvist, Verkasalo, \& Nissinen, 2013; Paulhus \& Reynolds, 1995). However, our summary of evidence in Table 1 demonstrates that this conclusion is premature: Calculating the sample size-weighted, metaanalytic correlations (Field, 2001; Hunter \& Schmidt, 1990) across studies shows that actually two traits yielded considerable levels of assumed similarity, namely Agreeableness and Openness. Indeed, for both trait dimensions, our meta-analytic summary reveals almost

\footnotetext{
${ }^{2}$ In our meta-analytic summary, we excluded studies measuring the FFM traits with a single adjective per factor only (Albright et al., 1988; Kenny, 1994; Malloy \& Albright, 1990) given that such measures only capture a single aspect - and thus a very small fraction - of these broad personality dimensions. Nonetheless, these studies also provide support in line with the overall pattern of relations summarized in Table 1. Moreover, we excluded studies focusing on the level of assumed similarity across basic traits without referring to trait-specific effects (Human \& Biesanz, 2011; Locke, Craig, Baik, \& Gohil, 2012; Rogers \& Biesanz, 2014; Selfhout et al., 2009).
} 
equivalent and medium-sized correlations (i.e., $\bar{r}=.25$ and $\bar{r}=.23$ ). For the remaining FFM traits, in turn, assumed similarity correlations were substantially smaller on average (all $\bar{r} \leq$ $.13) .^{3}$

Complementing and extending these findings, evidence on assumed similarity among the HEXACO personality traits (Honesty-Humility, Emotionality, Extraversion, Agreeableness, Conscientiousness, and Openness to Experience) likewise reveals consistent assumed similarity correlations for only two traits, namely Honesty-Humility $(\bar{r}=.48)$ and Openness to Experience $(\bar{r}=.35)$. In general, the HEXACO model represents an extended and modified variant of the FFM, with Honesty-Humility being added as a new, sixth factor and Emotionality and Agreeableness reflecting rotated versions of their FFM counterparts (e.g., Ashton \& Lee, 2007; Ashton et al., 2014). Honesty-Humility captures individual differences in prosocial and moral behaviors and thus has clear overlap with FFM-Agreeableness, although adding some content that is not accommodated by any FFM trait (Ashton \& Lee, 2008, 2018; Lee, Ogunfowora, \& Ashton, 2005). ${ }^{4}$

Overall, prior evidence on assumed similarity among basic personality traits thus reveals a highly consistent pattern, implying that self-descriptions are mostly related to judgments of others on FFM-Agreeableness and HEXACO Honesty-Humility, respectively, as well as on Openness to Experience (simply termed "Openness" in what follows). In turn,

\footnotetext{
${ }^{3}$ Importantly, the pattern of results reported in Table 1 remains the same once applying a correction for attenuation (Spearman, 1904) to the raw correlations to account for measurement error (see Table O14 in the OSF materials; note that correcting for unreliability was only possible for a subset of studies given the lack of exact alpha reliabilities for some studies). This demonstrates that the differences in assumed similarity across trait dimensions cannot be attributed to corresponding differences in (un)reliability.

${ }^{4}$ In line with its theoretical conceptualization, Honesty-Humility has been consistently linked - and more strongly so than FFM-Agreeableness - to different prosocial and moral behaviors such as fairness and cooperation (e.g., Pfattheicher \& Böhm, 2018; Thielmann \& Hilbig, 2015, 2018; Zhao \& Smillie, 2015), honesty (e.g., Heck, Thielmann, Moshagen, \& Hilbig, 2018; Hilbig \& Zettler, 2015; Kleinlogel, Dietz, \& Antonakis, 2018), low levels of workplace delinquency and counterproductive work behavior (e.g., Ashton \& Lee, 2008; Lee, Ashton, Morrison, Cordery, \& Dunlop, 2008; Marcus et al., 2007), and low levels of dark personality traits (e.g., De Vries \& van Kampen, 2010; Lee et al., 2013; Moshagen, Zettler, \& Hilbig, 2018).
} 
especially the findings indicating assumed similarity in FFM-Agreeableness and HonestyHumility are also well in line with findings revealing assumed similarity for more specific traits related to entitlement, greed, insincerity, manipulativeness, and mistrust (Kenny \& Kashy, 1994; Ready et al., 2000).

In addition to trait-specific effects of assumed similarity, evidence suggests that assumed similarity also differs as a function of the relationship between rater (person A) and target (person B). Specifically, it has been repeatedly shown that assumed similarity is stronger in close relationships (Kenny, 1994; Kenny \& Kashy, 1994; Lee et al., 2009; Selfhout, Denissen, Branje, \& Meeus, 2009; Srivastava, Guglielmo, \& Beer, 2010). For instance, Selfhout and colleagues (2009) found that the level of assumed similarity was positively related to friendship intensity, and Lee and colleagues (2009) observed stronger assumed similarity among friends as compared to non-friend acquaintances. In principle, one could argue that higher levels of assumed similarity among close others is attributable to higher levels of actual similarity, given that people might form closer relationships with others who are similar to themselves (Murray, Holmes, Bellavia, Griffin, \& Dolderman, 2002; Paunonen \& Hong, 2013). However, evidence on whether individuals are more likely to have close relationships with others who have similar personality characteristics is actually mixed (e.g., Beer et al., 2013; Gonzaga, Campos, \& Bradbury, 2007; Leikas, Ilmarinen, Verkasalo, Vartiainen, \& Lönnqvist, 2018; Luo \& Klohnen, 2005; Mollgaard et al., 2016; Rushton \& Bons, 2005; Watson et al., 2004, 2000; Youyou, Stillwell, Schwartz, \& Kosinski, 2017). More importantly, assumed similarity correlations are typically larger than actual similarity correlations on corresponding traits (e.g., T. R. Cohen, Panter, Turan, Morse, \& Kim, 2013; Paunonen \& Hong, 2013; Watson et al., 2000), and accounting for actual similarity in assumed similarity correlations has been found to still reveal meaningful levels of assumed similarity among well-acquainted others (e.g., Lee et al., 2009; Liu, Ludeke, \& Zettler, in 
press). This implies that higher levels of assumed similarity among close others cannot be (fully) accounted for by higher levels of actual similarity.

\section{Theoretical accounts of assumed similarity}

To explain assumed similarity in personality judgments, different theoretical accounts have been proposed. In what follows, we will focus on those accounts that have been primarily discussed in prior research on assumed similarity of personality traits and its traitspecific nature, namely, lack of information, relevance to personal values, and known/spurious similarity. However, note that especially in the social psychological literature on social projection, other accounts have been discussed, which particularly aim at identifying the situational factors that may moderate the degree of social projection. ${ }^{5}$ Nonetheless, "of the many mechanisms that have been proposed to explain projection, $[\ldots]$ none, however, has turned out to be necessary for social projection to occur" (Robbins \& Krueger, 2005, p. 32), and we therefore focus on the most prominent accounts proposed in personality research.

First off, the lack-of-information account suggests that individuals will refer to their own personality to judge others whenever they have insufficient other information available to form a corresponding judgment. Thus, according to this view, assumed similarity basically reflects a "lack-of-information effect" (Kenny \& West, 2010): Whenever individuals have insufficient information to judge another's personality, they might use their own trait level as an additional source of information (e.g., Beer \& Watson, 2008; Paunonen \& Kam, 2014; Ready et al., 2000; Watson et al., 2000). More detailed, corresponding to a lens model approach (Brunswik, 1952), raters require cues that are probabilistically related to a trait in question to form a corresponding personality judgment. However, traits differ in the number and validity of cues they provide - for instance, traits differ with regard to their visibility, that

\footnotetext{
${ }^{5}$ For instance, it has been argued that individuals will project their own characteristics onto others whenever they experience anxiety and therefore have a high need for social connectedness (Arndt, Greenberg, Solomon, Pyszczynski, \& Schimel, 1999).
} 
is, the degree to which they are reflected in overt (observable) behaviors (Funder \& Dobroth, 1987; Paunonen, 1989; Vazire, 2010) - and are thus more or less predictable for observers. By implication, assumed similarity should be particularly high for those traits being hardly predictable due to providing only few (if any) observable cues to raters. Conversely, "when traits are highly visible, perceivers need not rely on the self to base their perceptions of others" (Kenny \& West, 2010, p. 208), thus implying assumed similarity to be absent for traits offering sufficient information to observers.

In line with this reasoning, meta-analytic evidence (Kenny \& West, 2010) suggests a negative relation between assumed similarity and availability of trait-relevant information about a target, implying that assumed similarity is stronger the less cues raters have at their disposal to form a personality judgment. Moreover, assumed similarity has been found to be inversely related to self-other agreement (Beer \& Watson, 2008; Leikas et al., 2013; Ready et al., 2000; Watson et al., 2000; but see Paunonen \& Hong, 2013, for counterevidence). Thus, the lower the accuracy of a personality judgment - which, in turn, implies a lower level of valid information about the target - the higher is assumed similarity.

However, the finding that assumed similarity increases with relationship closeness - and thus whenever raters arguably have more rather than less valid information about the target is actually incompatible with the lack-of-information account. Likewise, although the lack-ofinformation account can, in principle, explain trait-specific effects of assumed similarity based on differences in trait predictability, it cannot explain the comparably low level of assumed similarity for FFM-Neuroticism (see Table 1). Specifically, meta-analytic evidence on the accuracy of personality judgments at zero acquaintance shows that this trait in particular is difficult to judge for observers (Connelly \& Ones, 2010; Connolly, Kavanagh, \& Viswesvaran, 2007), suggesting a low level of predictability unless targets are specifically placed in trait-relevant (i.e., socially stressful) situations (Hirschmüller, Egloff, Schmukle, Nestler, \& Back, 2015). Thus, if lack of information is the driving force underlying assumed 
similarity, correlations between one's self- and observer ratings about another person should also be substantial for Neuroticism because raters arguably lack sufficient information - at least when raters do not have a close relationship with the target. Importantly, note that this reasoning does not necessarily apply to the counterpart of Neuroticism within the HEXACO model, that is, Emotionality: For Emotionality, self-other agreement is usually substantial (e.g., De Vries, 2010; Lee \& Ashton, 2006, 2017; Thielmann, Zimmermann, Leising, \& Hilbig, 2017), implying a relatively high visibility of this dimension and thus predictability of related characteristics.

An alternative account that can explain both trait- and relationship-specific effects of assumed similarity has been proposed by Lee and colleagues (2009). Based on evidence from the HEXACO personality model, the authors suggest that assumed similarity on HonestyHumility and Openness might result from the specific relation of these traits to the two basic dimensions of personal values (Schwartz, 1992), Self-Enhancement versus SelfTranscendence and Openness to Change versus Conservation (Anglim, Knowles, Dunlop, \& Marty, 2017; Lee, Ashton, Ogunfowora, Bourdage, \& Shin, 2010). Indeed, these two value dimensions showed a highly similar pattern of assumed similarity as their HEXACO counterparts Honesty-Humility and Openness. The authors thus concluded that because "values are an important part of people's social relationships [...] people tend to assume that their values are shared by those with whom they have close relationships" (Lee et al., 2009; p. 469). This implies that assumed similarity does not simply result from a lack of information, but rather that individuals (want to) assume or believe that others - especially close others are similar to themselves on traits bearing high personal relevance. As such, the value account provides a straightforward explanation for higher levels of assumed similarity with increasing relationship closeness. Indeed, the account has been particularly proposed to explain assumed similarity among well-acquainted others: Because people are motivated to believe that close others share their values (Murray et al., 2002), they should be particularly inclined to refer to 
their own (value-related) personality traits when rating the personality of close others. Importantly, note that the value account is also fully compatible with evidence on assumed similarity among the FFM traits as FFM-Agreeableness and Openness are likewise specifically related to the two major dimensions of personal values (Fischer \& Boer, 2015), although slightly weaker than Honesty-Humility and HEXACO-Openness.

Beyond these theoretical accounts of assumed similarity, Paunonen and Hong (2013) presented another, more critical perspective on how to explain the emergence of assumed similarity correlations. Specifically, the authors proposed that "in most person perception contexts, 'true' assumed similarity representing untested assumptions about self-other likeness, is probably rare" (p. 800). In turn, assumed similarity correlations may largely result from other sources than from raters' tendency to refer to their own personality when rating others. According to Paunonen and Hong (2013), correlations between a rater's self- and observer ratings will be strongly affected by known similarity and spurious similarity. Whereas known similarity refers to judgments based on knowledge about actual similarity with the target person, spurious similarity refers to judgments based on information about the target's group membership (e.g., sex, education, ethnical background, personal interests). Importantly, both judgmental processes are made without any reference to one's own personality, thus disagreeing with the psychological understanding of assumed similarity. For example, when students are asked to judge the personality of other students, a positive assumed similarity correlation might simply result from the fact that raters and targets are all students (and one group judging the others' traits by means of the latter's group membership as students), thus spuriously causing a certain congruence in the personality ratings without requiring that the raters in any way referred to their own personality when rating the targets.

However, although known similarity and spurious similarity may indeed contribute to the occurrence of assumed similarity correlations, Paunonen and Hong (2013) themselves acknowledge that the trait-specific effects of assumed similarity on traits that are strongly 
related to personal values (Lee et al., 2009) "seems reasonable [only] from an ego maintenance point of view" (p. 813). In other words, if correlations between self- and observer reports were primarily due to known and spurious similarity, it is at least highly unlikely that assumed similarity correlations are consistently observed for two traits only. Moreover, known similarity can, by definition, only affect assumed similarity whenever rater and target person know each other. Thus, the finding that assumed similarity is also apparent when individuals judge the personality of strangers (e.g., Albright et al., 1988; Beer \& Watson, 2008; Kenny, Horner, Kashy, \& Chu, 1992; Rogers \& Biesanz, 2014) cannot be attributed to known similarity. Overall, evidence thus supports the presence of "true" assumed similarity in personality judgments, although corresponding correlations may well be inflated by known and spurious similarity.

\section{The present investigation}

The goal of the studies reported in what follows was to thoroughly test the presented competing accounts of why assumed similarity in personality judgments occurs. As detailed above, different accounts (i.e., lack of information, relevance to personal values, and known/spurious similarity) have been proposed in prior research to explain the recurring finding that individuals' self-reports on some traits are positively linked to their judgments of others on these same traits. However, direct empirical tests of these accounts are scarce, and studies testing the different accounts against each other are, to the best of our knowledge, entirely missing. In a set of nine studies, we aimed to close this gap and to thereby shed light on how to account for assumed similarity in personality judgments.

On the level of traits, we relied on the HEXACO dimensions given that (i) prior research on assumed similarity of basic traits has been most consistent for the HEXACO dimensions (see Table 1) and (ii) Honesty-Humility and Openness show particularly strong links to personal values, thus allowing for a more direct test of the value account. On the level of the target persons, in turn, we primarily focused on unacquainted others (although also 
implementing a comparison to acquaintances in Study 1), and systematically varied the amount of information participants received about the target persons across studies (i.e., meeting another personally vs. seeing a picture of another vs. imagining another) to provide a specific test of the lack-of-information account. A key advantage of using strangers as target persons is that all raters necessarily have the same amount of information about and also the same (namely, no) relationship with the targets. By implication, this prevents that personality judgments are inflated by known similarity or by systematic effects resulting from differences in relationship closeness between raters and targets. Note that, as such, the presented studies are the first to provide evidence on assumed similarity of the HEXACO dimensions among strangers, thereby testing whether the findings by Lee et al. (2009) and their value account may generalize to judgments of strangers. Finally, to ensure that assumed similarity correlations are not artificially inflated by actual similarity between raters and targets (which raters need not be aware of but which might still inflate assumed similarity), we took actual similarity into account by (a) partialing out the effect of targets' self-reports when predicting raters' observer reports and by (b) comparing assumed similarity with actual similarity correlations (Paunonen \& Hong, 2013).

In general, note that because assumed similarity is, by definition, a positive effect (i.e., a positive relation between a rater's self-report and her observer report of a target person), all assumed similarity correlations and main effects in multiple regression analyses will be tested one-tailed. Correspondingly, we will only report $p$-values for positive assumed similarity effects but not for negative effects. For all studies, we provide the instructions and materials as well as the data and complementing analyses online at the Open Science Framework (OSF; https://osf.io/hxt7r/). Moreover, in all our studies we adhere to the ethical guidelines on research with human participants (note that the approval of studies by a research ethics committee is not required in Germany).

\section{Study 1}


Study 1 aimed at comparing assumed similarity across different target persons with varying levels of acquaintanceship, namely, acquainted others (i.e., roommates and fellow students) versus strangers. As such, the study extended prior research on the link between assumed similarity and relationship closeness by not only incorporating personality ratings of different types of acquainted others with varying levels of relationship closeness (e.g., Lee et al., 2009; Selfhout et al., 2009; Watson et al., 2000), but by additionally including a rating of a complete stranger. Thereby, the study allowed for a specific and targeted test of the lack-ofinformation account: As individuals have much more information available about (well)acquainted others than about a stranger, the lack-of-information account would predict higher levels of assumed similarity when rating a stranger as compared to when rating a roommate or a fellow student. Furthermore, reliance on the HEXACO dimensions enabled testing the predictions of the value account that assumed similarity should primarily occur for HonestyHumility and Openness as well as whether this actually holds for both acquainted and unacquainted others. Finally, taking into account actual similarity between rater and target in the judgment of acquainted others allowed us to draw conclusions on whether known/actual similarity indeed artificially increases corresponding assumed similarity correlations.

\section{Method}

\section{Procedure and materials}

Individuals (targets) were invited to the laboratory of a German university and asked to bring a roommate as well as a fellow student. To ensure different levels of relationship closeness among the two acquainted raters, targets were specifically asked to bring a fellow student they know (and occasionally spend some time with), but not too well. In addition, we assigned a random other to each acquainted triad who was unknown to the target person (as well as to her roommate and fellow student). To ensure that the randomly assigned other and the target were indeed complete strangers, we (i) recruited the random others from another group of students than the target persons and (ii) ensured that the random other and 
corresponding target were from different fields and years of study. The roommates, fellow students, and strangers assigned to each target represented the participants of the current investigation, and they will be called "raters" in what follows. That is, targets were judged by three raters: two acquaintances (a roommate and a fellow student) and a stranger.

As soon as all participants comprising a quartet (i.e., the acquainted triad of target, roommate, and fellow student as well as the random other) had arrived, the experimenter guided the participants to the laboratory. Participants were seated such that the target person was placed on one side of the room and the three raters on the other side. Target and raters sat back to back to one another to ensure that they could not see each other while they provided their rating. Also, note that the experimenter took great care that participants did not communicate with each other from arrival onwards. This ensured that the random other and the target person saw each other only briefly prior to their rating (about 90sec from being welcomed to being seated), without having any opportunity to truly interact with each other.

First, all participants provided informed consent and demographic information.

Thereafter, the three raters were asked to complete observer reports of the target's personality traits and to answer some questions on their relationship with the target person, including how long they had known the target and how well they knew the target (on a 10-point Likert typescale ranging from $1=$ "not at all" to $10=$ "very well"). Finally, raters were asked to complete a self-report of their personality. In the meantime, targets provided a self-report of their personality as well as meta-perceptions about their personality from the perspective of their roommate, their fellow student, and the assigned stranger. These meta-perceptions were collected within the scope of another research project and are thus not further considered in what follows. As a compensation for participation, all participants (i.e., raters and targets) received $12 €$ (approx. 16.50 US\$ at the time of data collection).

To assess self- and observer reports of individuals' personality traits, we used the SelfReport Form and the Observer-Report Form of the German version (Moshagen, Hilbig, \& 
Zettler, 2014) of the 60-item HEXACO Personality Inventory-Revised (HEXACO-60; Ashton \& Lee, 2009). The HEXACO-60 contains 10 items to measure each of the six HEXACO dimensions. Items are answered on a five-point Likert type scale ranging from $1=$ "strongly disagree" to $5=$ "strongly agree". All scales yielded satisfactory internal consistencies in the current study (i.e., all Cronbach's $\alpha \geq .68$; for details, see Table O1 in the OSF materials).

\section{Participants}

To determine the required sample size, we conducted an a priori power analysis using G*Power (Faul, Erdfelder, Buchner, \& Lang, 2009). Based on our meta-analytic estimates of assumed similarity correlations for the HEXACO dimensions (Table 1), we considered an effect size of $r=.35$ (as observed for Openness) to be tested in a one-tailed $t$-test for correlations $^{6}$ with $\alpha=.05$ and satisfactory power of $1-\beta=.80$ to reveal a reasonable estimate of the minimum required sample size for the current study. This resulted in $N=49$, which corresponds to the number of ratings needed per group of raters (i.e., roommates, fellow students, and strangers). However, note that for all analyses exploiting the entire data - thus using the repeated measures of targets' personality traits by the three raters in a multilevel approach - this estimate is arguably conservative.

Corresponding to the power analysis, we recruited $N=57$ targets who were judged by three raters each, thus resulting in a total of 170 raters. ${ }^{7}$ All participants were students at a large German university. The majority of raters and targets were female (i.e., $82.5 \%$ and $73.5 \%$, respectively), and they were aged between 19 and 32 years $\left(M_{\text {raters }}=23.3, S D_{\text {raters }}=\right.$ $2.5 ; M_{\text {targets }}=22.2, S D_{\text {targets }}=2.2$ ). Demographics were highly comparably across the three groups of raters. The relation between raters and targets nicely mirrored the pattern of relationship closeness intended across groups of raters: Roommates indicated knowing the

\footnotetext{
${ }^{6}$ In all our power analyses and statistical tests reported in what follows, we test against the null hypothesis of $\rho=0$.

${ }^{7}$ For one target person, no rating by the roommate was obtained. Thus, the overall number of observer ratings was 170 (i.e., 57 targets $* 3$ informants -1 ).
} 
target person longest $(M=52.6$ months, $S D=67.5)$ and best $(M=8.7, S D=1.1)$, followed by the fellow students (length: $M=22.6$ months, $S D=12.8$; knowledge: $M=5.8, S D=1.6$ ), and the strangers who did not know the target persons at all (length: $M=0.0$ months, $S D=0.0$; knowledge: $M=1.0, S D=0.1)$. All pair-wise comparisons of length and level of acquaintance across raters were significant at $p \leq .001$.

\section{Results and discussion}

Table 2 summarizes the zero-order correlations between raters' self-reports and their observer reports of the targets (assumed similarity) as well as between raters' and targets' self-reports (actual similarity; for descriptive statistics, internal consistencies, and intercorrelations between all personality ratings assessed, see Table O1 in the OSF materials). As is apparent, across all groups of raters, assumed similarity correlations were largest for Honesty-Humility, revealing medium-sized to large effects (J. Cohen, 1988). Moreover, Openness showed substantial assumed similarity correlations across raters (all $r>.20$ ), although only reaching a conventional level of statistical significance for roommates and fellow students - and thus for raters knowing the target person relatively well. Across the remaining HEXACO dimensions, we only found assumed similarity for the rating of Extraversion by the fellow student. All other assumed similarity correlations fell below $r=$ |.13|. Thus, the zero-order correlations were generally well in line with prior research on assumed similarity of the HEXACO dimensions (Table 1) and thus also with the value account.

The level of actual similarity between raters and targets, in turn, was generally low, with a slight tendency for acquaintances to be more similar to each other as compared to complete strangers. Specifically, significant actual similarity correlations were only apparent on Honesty-Humility for roommates and on Conscientiousness for roommates and fellow students. For the strangers, we observed no actual similarity with the targets whatsoever. Correspondingly, assumed similarity correlations remained highly similar in size when 
controlling for actual similarity between raters and targets by partialing out the targets' selfreports (correlations in parentheses in Table 2). Descriptively comparing the pattern of assumed and actual similarity correlations further revealed some interesting insights: For instance, despite a considerable level of actual similarity between roommates as well as fellow students and targets on Conscientiousness, the raters failed to assess this similarity, as the (zero-order) assumed similarity correlations for Conscientiousness were close to zero. Conversely, the strongest assumed similarity correlations were apparent for the rating of the fellow students and strangers on Honesty-Humility for which, in turn, actual similarity with the target was virtually non-existent. This suggests that assumed similarity as observed in our study was not attributable to or artificially inflated by actual similarity between raters and targets.

Finally, to test whether assumed similarity on Honesty-Humility and Openness differed across groups of raters, we ran a multilevel regression analysis using the lme 4 package (Bates, Maechler, Bolker, \& Walker, 2014) in R. Specifically, we regressed raters' observer reports of a target's trait on their self-report of the trait, two dummy variables coding the raters' relation to the target (dummy $1=0,0,1$ and dummy $2=0,1,0$ for stranger, fellow student, and roommate, respectively), the interaction between raters' self-report and the two dummy variables, and the targets' self-report. All predictor variables were centered on the sample mean, and we ran separate models for Honesty-Humility and Openness.

In line with the zero-order correlations, the multilevel regression on Honesty-Humility again revealed significant assumed similarity across raters as indicated by a significant main effect of raters' self-reports, $B=0.67, p<.001$. Implying that the strength of assumed similarity was similar across raters, there was no significant interaction between rater's selfreport and the two dummy variables coding the type of relationship, $B=0.22, p=.163$ and $B$ $=-0.02, p=.871$, respectively. For Openness, in turn, the analysis likewise yielded a main effect of raters' self-reports, $B=0.48, p<.001$, thus supporting that assumed similarity was 
also apparent for this trait dimension. However, in contrast to Honesty-Humility, raters' selfreports significantly interacted with the two relationship dummy variables, $B=0.63, p<.001$ and $B=0.39, p=.002$, respectively. This demonstrates that assumed similarity was indeed larger for both roommates and fellow students as compared to strangers.

The findings of Study 1 can be summarized as follows: Across different groups of raters with varying levels of relationship closeness, assumed similarity was only consistently apparent for two traits, namely Honesty-Humility and Openness. As such, the findings replicate prior studies on assumed similarity among the HEXACO dimensions (Table 1) and are overall compatible with the predictions of the value account. Of note, this was even the case for the rating of the stranger's personality although, as mentioned above, the value account was originally proposed to explain assumed similarity among well-acquainted others. In turn, the finding that assumed similarity was partially (i.e., for Openness) weaker for strangers than for acquainted others is incompatible with the idea that assumed similarity basically represents a lack-of-information effect. According to the lack-of-information account, assumed similarity correlations should be particularly high when individuals have insufficient information available to judge another's personality, that is, when raters hardly know the target. In our study, there was no evidence for an increasing level of assumed similarity in unknown others, and even the exact opposite was apparent for the judgment of Openness. Finally, the results were also incompatible with the idea that a considerable portion of assumed similarity among acquainted others is due to known/actual similarity. Rather, assumed similarity was particularly apparent for judgments of (well-)acquainted others on those HEXACO traits that are strongly related to personal values, irrespective of whether rater and target indeed resembled each other.

\section{Study 2}

A key finding of Study 1 was that assumed similarity is also restricted to HonestyHumility and Openness when judging the personality of a complete stranger. As summarized 
above, prior studies on assumed similarity of the HEXACO dimensions have exclusively focused on judgments of acquainted others, and evidence on assumed similarity of the FFM dimensions among unacquainted others is somewhat mixed, with some studies indeed pointing to assumed similarity on other traits than FFM-Agreeableness and Openness (see Table 1). Thus, we considered it vital to specifically replicate said finding, that is, traitspecific assumed similarity in personality judgments among strangers. Thereby, Study 2 provided another direct test of the lack-of-information account vis-à-vis the value account, although focusing on personality judgments among unacquainted individuals only: Given that raters have very limited information about strangers in general, the lack-of-information account would predict that assumed similarity is also apparent for other traits than HonestyHumility and Openness because other traits should be just as difficult to judge due to a very limited extent of trait-relevant information available. By contrast, the value account - if it also applies to judgments of strangers, as implied by Study 1 - specifically predicts that assumed similarity is predominantly found for the two primary, value-related traits in the HEXACO model, Honesty-Humility and Openness.

\section{Method}

\section{Procedure and materials}

The study was conducted as a lab-based experiment at a German university (another than in Study 1). Participants were invited to sessions comprising groups of at least four individuals. To ensure that some participants were unknown to each other in each session, participants were recruited via university mailing lists and social networks from different classes.

Upon arrival, participants were seated in front of a computer in separate cubicles and asked to provide informed consent, demographic information, and a self-report of the HEXACO dimensions. Unlike in Study 1, we used the 100-item version of the HEXACO-PIR (HEXACO-100; Lee \& Ashton, 2016) in Study 2 to allow for a more reliable assessment of 
the HEXACO traits (all $\alpha \geq .74$; for details, see Table O2 in the OSF materials). Following completion of the self-report, participants were asked to turn around with their chair and to form a circle such that all participants were able to see each other. Next, participants received the instruction to select another participant in the room who was unknown to them and to rate the personality of this person using a paper-pencil version of the HEXACO-100 ObserverReport Form (all $\alpha \geq .79$; see Table O2). To allow for matching of participants' observer reports with the targets' self-reports, all participants received a badge with their unique participant ID to be placed visibly on their top, and participants were asked to note the ID of their target person on the observer report questionnaire. Participants also indicated whether they knew the target person. After completing the observer report, participants were asked to turn back to their computer and to answer some questions concerning the seriousness of their participation, including two questions on the subjective effort they had invested in the personality rating task. As compensation for participation, participants received course credit and, if desired, feedback on their individual personality profile.

\section{Participants}

Based on the findings from Study 1, we conducted an a priori power analysis using $\mathrm{G}^{*}$ Power (Faul et al., 2009), specifying a slightly smaller effect size of $r=.30$ (i.e., average assumed similarity across Honesty-Humility and Openness for the stranger rating in Study 1) to be detected in a one-tailed $t$-test for correlations with a conventional $\alpha=.05$ and satisfactory power of $1-\beta=.80$. This revealed a required sample size of $N=67$. Correspondingly, we recruited $N=71$ participants. However, one person had to be excluded due to indicating careless responding on both questions assessing the seriousness of their personality judgments, resulting in a final sample of $N=70$. The majority of participants were female $(80.0 \%)$, and they were aged between 18 and 52 years $(M=22.0, S D=5.5)$. Almost all participants $(95.7 \%)$ were students. As intended, raters and targets were almost always 
strangers: Only $n=7$ participants indicated that they had seen their target person before. ${ }^{8}$ None indicated ever having interacted with each other.

\section{Results and discussion}

Table 3 summarizes the zero-order (and partial) correlations for assumed similarity of raters and actual similarity between raters and targets (for descriptive statistics, internal consistencies, and inter-correlations between all variables, see Table O2 in the OSF materials). As is apparent, Honesty-Humility again yielded the largest assumed similarity effect $(r=.21, p=.043)$, followed by Openness $(r=.09, p=.228)$. However, both correlations (and especially the one for Openness) were weaker as observed in Study 1, and the assumed similarity effect for Openness failed to reach a conventional level of statistical significance. For the remaining HEXACO dimensions, assumed similarity correlations were either slightly negative or close to zero. Partialing out targets' self-report from assumed similarity to account for actual similarity between rater and target essentially led to the same results, with $r_{p}=.21, p=.044$, for Honesty-Humility and $r_{p}=.10, p=.200$, for Openness. In turn, actual similarity correlations were generally small, except for Openness which showed a medium-sized negative correlation - and thus dissimilarity - between raters' and targets' selfreports.

In summary, Study 2 replicated the pattern of assumed similarity correlations observed in Study 1, albeit with noticeably smaller effect sizes. Nonetheless, the findings imply that even with very limited information available, assumed similarity is limited to a subset of traits, namely Honesty-Humility and (to a lesser extent) Openness. Although the correlation coefficient for Openness was only small in size (J. Cohen, 1988) and non-significant, this finding must be interpreted bearing in mind the medium-sized negative actual similarity correlation observed. That is, although raters and targets were actually dissimilar with regard

\footnotetext{
${ }^{8}$ Results remained virtually the same when excluding these participants from the analyses.
} 
to their level of Openness, ratings nonetheless reflected some similarity with the target person. Thus, the results are again generally compatible with the value account. In turn, the findings can neither be accounted for by the lack-of-information account, nor be fully accommodated by actual similarity (or known similarity, given that raters and targets were essentially strangers).

\section{Study 3}

Although Study 2 descriptively replicated the pattern of results observed in Study 1, a limitation of Study 2 is that participants selected their target person themselves. This might have encouraged participants to choose a target they perceived to be dissimilar to themselves (and thus, we speculate, more "interesting") - which could, for instance, explain why we observed a substantial dissimilarity between raters and targets on Openness. The objective of Study 3 was to overcome this limitation and to further decrease the information available to raters for their personality judgment by simply presenting raters with a photograph of an unknown individual who served as the target person. The design thus allowed for an even stricter test of the lack-of-information account vis-à-vis the value account: Given that a photograph arguably conveys even less information than is available when actually meeting a person - it only provides a single slice and thus little to no information about an individual's gestures, facial expressions, or voice (see, e.g., Vazire, Naumann, Rentfrow, \& Gosling, 2008, for similar reasoning) - the lack-of-information account still more clearly implies that assumed similarity should occur in general and not only for Honesty-Humility and Openness. The very contrary is predicted by the value account. Moreover, in Study 3 we used the full 192-item version of the HEXACO-PI-R to allow for a more fine-grained analysis of assumed similarity on the facet-level.

\section{Method}

\section{Procedure and materials}


The study was conducted as a lab-based experiment at a German university. Upon arrival, participants were seated in front of a computer in separate cubicles. After providing informed consent and demographic information, participants completed the German version of the full 192-item self-report form of the HEXACO-PI-R (Lee \& Ashton, 2006). The questionnaire contains 32 items to assess each of the six HEXACO dimensions. Each dimension is, in turn, composed of four facets which are measured by 8 items each. Again, all items were answered on a five-point Likert-type scale ranging from 1 = "strongly disagree" to $5=$ "strongly agree". Internal consistency reliabilities were satisfactory for both factor and facet scores (i.e., for factors, $\alpha \geq .84$, for facets $\alpha \geq .70$; for details, see Table O3 and Table O4 in the OSF materials).

After the self-report, participants were presented with a full-body photograph of an unknown target person and asked to rate the target using the Observer Report Form of the HEXACO-PI-R (192 items; all $\alpha \geq .82$ for the factors and $\alpha \geq .64$ for the facets; Table O3 and Table O4). The items were presented such that participants were able to permanently see the photo while providing their judgment. The photos were randomly drawn from a stimulus set containing pictures of 38 targets in total ${ }^{9}, 19$ male and 19 female individuals, displayed in their usual outfit and in a spontaneous pose (see, e.g., Naumann, Vazire, Rentfrow, \& Gosling, 2009). As part of the informed consent, targets explicitly agreed that the photographs could be used for scientific purposes such as being shown to other participants. For each target, self-reports on the HEXACO dimensions (as assessed via the HEXACO-60) were available. The stimulus set was collected at a different German university several years prior to the present study which renders it highly unlikely that raters were acquainted with the targets. Nonetheless, following the observer rating, we asked participants whether the target

\footnotetext{
${ }^{9}$ The full stimulus set from which targets were drawn actually contains 50 targets (see Study 4). However, given that the stimulus set only contains 19 male targets, we randomly selected 19 (from the 31) female targets to ensure that the stimuli used in the present study comprised an equal number of male and female targets.
} 
person was actually a stranger to them, and also included two questions assessing the seriousness of their personality rating. As compensation for participation, participants received course credit and, if desired, feedback on their individual personality profile.

\section{Participants}

Based on the results of Study 2, we aimed at collecting a slightly larger sample size as implied by the previous power analyses to further increase statistical power. Correspondingly, we recruited $N=84$ participants who were students at a German university. However, $n=3$ participants had to be excluded due to careless responding on the HEXACO observer report (i.e., $n=2$ participants required less than $2 \mathrm{sec}$ on average per item and $n=1$ participant indicated having only guessed and not responded seriously). Of the final sample $(N=81)$, $84.0 \%$ were female, they were aged between 18 and 29 years $(M=21.4, S D=2.6)$, and all participants were students (mostly psychology). As intended, all participants indicated that the target person was a complete stranger to them.

\section{Results and discussion}

Table 4 summarizes the zero-order and partial assumed similarity correlations as well as the actual similarity correlations for the HEXACO dimensions (for descriptive statistics, internal consistencies, and inter-correlations between all variables, see Table O3 in the OSF materials). As in Studies 1 and 2, the largest assumed similarity correlation was apparent for Honesty-Humility $(r=.26, p=.010)$, followed by Openness $(r=.13, p=.116)$ which was, however, again only small in size and failed to reach a conventional level of statistical significance. For all remaining HEXACO traits, assumed similarity correlations were either negative or close to zero. Importantly, this pattern of assumed similarity was not merely a reflection of actual similarity: Raters and targets only revealed considerable actual similarity on Agreeableness $(r=.28, p=.013)$ for which, however, assumed similarity was basically absent $(r=.06, p=.283)$. For Honesty-Humility, in turn, actual similarity was essentially zero $(r=.04, p=.714)$. A more inconclusive pattern was apparent for Openness, which revealed 
highly similar effect sizes for assumed and actual similarity. Nonetheless, accounting for actual similarity in the assumed similarity correlations (partial correlations; Table 4) resulted in virtually the same pattern of results, thus suggesting that assumed similarity was not simply driven by raters' accurate perception of actual similarity.

On the level of HEXACO facets, only four facets in total revealed significant assumed similarity correlations (Table 5). Mirroring the factor-level results, all these facets belonged to Honesty-Humility (fairness and greed-avoidance) and Openness (aesthetic appreciation and inquisitiveness). ${ }^{10}$ Interestingly, the creativity facet of Openness revealed a negative assumed similarity correlation $(r=-.13)$, thus arguably explaining the small overall effect of Openness on the factor-level. Across the remaining dimensions, the highest assumed similarity correlation was apparent for the forgivingness facet of Agreeableness, $r=.14, p=.112$.

In sum, the results again imply that even when individuals have no other information about a target person available than a single slice (a full-body photo), self-descriptions are only linked to observer reports when making judgments related to Honesty-Humility and Openness. As such, the findings are once again incompatible with the notion that assumed similarity reflects a lack-of-information effect: If individuals simply tried to fill in the gaps of information necessary to form a judgment, there is no reason to expect this happening for only two traits when rating a complete stranger based on a single photograph. As such, the recurring finding that assumed similarity is only robust for Honesty-Humility and - albeit clearly weaker - for Openness on both the factor- and facet-level is in line with the value account.

\section{Study 4}

${ }^{10}$ Given that targets provided their self-ratings on the HEXACO-60, it was impossible to take actual similarity into account on the facet-level. However, in light of the low level of actual similarity on the factor-level - and the high correspondence between zero-order and partial assumed similarity correlations (Table 4) - we maintain that it is highly unlikely that assumed similarity correlations at the facet-level were considerably affected by actual similarity. 
Our results so far are most aligned with the value account which suggests that assumed similarity is a matter of the links of traits to personal values. Specifically, Studies 1-3 overall showed that even among strangers, assumed similarity only occurs for those traits that are strongly linked to personal values (i.e., Honesty-Humility and Openness). However, as detailed above, it might be that assumed similarity correlations largely reflect spurious similarity rather than "true" assumed similarity (Paunonen \& Hong, 2013). That is, individuals might actually infer others' personality based on certain group memberships such as sex, ethnical background, or education. In turn, due to shared group membership of rater and target (e.g., if both are of the same sex or are students), a rater's self-report and her observer report of a target might be spuriously (positively) linked. Importantly, according to Paunonen and Hong (2013), spurious similarity need not affect all traits in equal measure but may operate on specific traits only. Thus, the trait-specific findings observed in Studies 1-3 (and prior research) could also be accounted for by spurious similarity rather than by true assumed similarity resulting from the trait-specific link to personal values as proposed by Lee et al. (2009). Thus, to test this alternative explanation, we next examined whether the strength of assumed similarity differs as a function of shared group membership between rater and target by manipulating the congruence between raters' and targets' sex.

\section{Method}

\section{Procedure and materials}

The study consisted of two parts. Specifically, we separated the collection of selfreports and observer reports of personality in time to rule out potential carry-over effects between the two ratings. Therefore, we recruited participants from a local participant pool who had already completed an online assessment of the HEXACO dimensions using the SelfReport Form of the German HEXACO-60 (all $\alpha \geq .70$; for details, see Table O5 in the OSF materials). Participants' responses from this online study were matched with their responses from the second part of the study via self-generated, pseudonymous IDs. 
The second part of the study containing the observer reports was conducted in the laboratory. Upon arrival, participants were seated in front of a computer in separate cubicles and asked to provide informed consent and demographic information. Thereafter, participants received detailed instructions on the rating task, which involved judging the personality of two target persons presented on photos (one male and one female, in counterbalanced order) using the Observer Report Form of the German HEXACO-60 (all $\alpha \geq .73$; Table O5). Photos were drawn from the same stimulus set as used in Study 3, although we now relied on the entire set containing 50 photographs in total (31 female and 19 male targets; see Footnote 9). To reiterate, the photos depicted individuals in their usual outfit and in a spontaneous pose, and we ensured that participants were able to permanently see the photo during the rating task. Following the two observer reports, participants were finally asked to answer some questions concerning their acquaintanceship with the targets and their seriousness of completing the observer reports. After the study, participants worked on other unrelated tasks not pertinent to the present research question. As a compensation for participation (including the online pre-study and the lab-based study), participants received $8 €$ (approx. 9.10US\$ at the time of data collection).

\section{Participants}

To determine the required sample size, we conducted an a priori power analysis using G*Power (Faul et al., 2009), based on the main objective of Study 4 to test the potential influence of spurious similarity and thus the interaction between raters' self-report and the congruence between raters' and targets' sex on raters' observer reports. Correspondingly, we specified a small to medium-sized effect of a single regression coefficient $\left(f^{2}=.09\right)$ in a multiple regression analysis with $k=3$ predictors as the primary effect under scrutiny, to be tested with a conventional alpha level of $\alpha=.05$ and satisfactory power of $1-\beta=.80$. This revealed a required sample size of $N=90$ participants. However, it should be noted that the statistical power to test said interaction was actually larger given that participants provided 
two observer reports each - thus allowing for application of multilevel procedures which fully exploit the information added by the repeated measurements per rater.

Corresponding to the sample size calculations, we recruited $N=97$ participants from a local participant pool at a German university. However, $n=2$ participants had to be excluded, one because her pseudonymous ID provided in the lab study could not be uniquely matched to the data from the online pre-study and another due to indicating careless responding on the observer report. The final sample thus comprised $N=95$ participants. The majority of these $(80.0 \%)$ were female, they were aged between 19 and 42 years $(M=22.5, S D=3.2)$, and all of them were students from diverse fields of study. All participants indicated that the targets were complete strangers to them.

\section{Results and discussion}

Table 6 displays the assumed similarity and actual similarity correlations as a function of the congruence between rater and target sex (for descriptive statistics, internal consistencies, and inter-correlations between all variables, see Table O5 in the OSF materials). As is apparent, only Honesty-Humility revealed significant assumed similarity correlations for both targets, with a descriptively larger correlation for the same sex target $(r=$ $.30, p=.001)$ as compared to the opposite sex target $(r=.18, p=.041)$. Importantly, these correlations were not attributable to actual similarity which was essentially zero for HonestyHumility. Correspondingly, the partial correlations accounting for actual similarity were highly similar to the zero-order correlations. By contrast, results for Openness revealed no evidence for assumed similarity whatsoever. Although this finding must also be qualified by the slight negative actual similarity correlation observed for this trait dimension, it once again shows that the assumed similarity effect for Openness seems to be less robust than the one occurring for Honesty-Humility.

Among the remaining trait dimensions, only Emotionality showed a significant level of assumed similarity for the same sex target $(r=.41, p<.001)$. However, this reversed into 
strong assumed dissimilarity for the opposite sex target $(r=-.46)$. Interestingly, the exact same correlational pattern was apparent for actual similarity between rater and target. Plausibly, this pattern is attributable to spurious similarity: Given that women typically score higher on Emotionality than men (e.g., Ashton \& Lee, 2007; Lee \& Ashton, 2016; Moshagen et al., 2014) - which raters are probably aware of - raters might have simply used the targets' sex as a (valid) cue to infer the targets' level of Emotionality.

To more conclusively test whether spurious similarity indeed contributed to assumed similarity correlations observed for Emotionality and also Honesty-Humility - which, as mentioned above, likewise showed a slight tendency for higher assumed similarity among same sex rater-target dyads - we relied on a multilevel regression analysis using the lme4 package (Bates et al., 2014) in R. Specifically, the regression model predicted raters' observer reports of the targets' personality by raters' self-reports, a dummy variable coding (in)congruence between rater and target sex $(0=$ opposite sex, $1=$ same sex $)$, and their interaction as well as targets' self-reports (to account for actual similarity). All predictor variables were centered on the sample mean. For Honesty-Humility, the model revealed a significant main effect of raters' self-reports, $B=0.30, p=.002-$ mirroring the assumed similarity effect - but no interaction between raters' self-reports and the dummy variable coding (in)congruence between rater and target sex, $B=0.15, p=.363$. This implies that the observed relation between raters' self-report and their observer reports of the targets' Honesty-Humility level cannot be fully accounted for by spurious similarity, but rather suggests true assumed similarity. This is especially important to note as women usually score slightly higher on Honesty-Humility than men (e.g., Lee \& Ashton, 2006, 2016; Moshagen et al., 2014) - a pattern that was also apparent in our sample, albeit only as a descriptive trend (women: $M=3.54, S D=0.57$; men: $M=3.37, S D=0.52 ; t(93)=1.16, p=.248, d=0.30$ ) which is why assumed similarity correlations may be (spuriously) inflated for ratings of samesex targets and suppressed for ratings of opposite-sex targets, respectively. By contrast, for 
Emotionality, the multilevel model yielded no main effect of judges' self-report, $B=-0.05, p$ $=.240$, but a significant interaction between judges' self-report and (in)congruence of individuals' sex, $B=0.79, p<.001$. Thus, the observed pattern of assumed (dis)similarity in Emotionality might indeed be attributable to spurious rather than to true assumed similarity. In summary, Study 4 replicated the finding that assumed similarity among the HEXACO dimensions is strongest for Honesty-Humility and further showed that this effect cannot be fully accounted for by spurious similarity. This is again compatible with the value account which predicts that the strong link of Honesty-Humility to personal values makes this trait dimension particularly susceptible to assumed similarity. By contrast, Study 4 did not demonstrate assumed similarity for Openness. However, it must be noted that Studies 1-3 also failed to convey a consistently positive picture for the assumed similarity effect of Openness: Repeatedly, the effect was relatively small and correspondingly fell short of reaching a conventional level of statistical significance. The current findings reflect this mixed pattern, implying that assumed similarity for Openness when rating strangers is weak at best, though still more pronounced than for the remaining traits overall.

As a novel finding, the study yielded a significant assumed similarity correlation for the judgment of a same sex target on Emotionality. However, this effect was most plausibly driven by spurious similarity, thus supporting the idea that assumed similarity correlations can indeed be spuriously inflated by raters' tendency to infer a target's personality based on her group membership. Finally, the results were once again incompatible with the lack-ofinformation account as only one trait (Honesty-Humility) revealed consistent evidence for assumed similarity across targets, despite the generally limited information available about the targets.

\section{Study 5}

Study 4 provided initial evidence that assumed similarity correlations might be somewhat conflated by spurious similarity. The objective of Study 5 was to provide another 
test of this possibility, using a different experimental approach and obtaining higher statistical power to also more conclusively test null results. In particular, we indeed observed a slight difference in the assumed similarity correlations for Honesty-Humility across same sex and opposite sex targets in Study 4 (i.e., $r=.30$ vs. $r=.18$ ). However, as the corresponding interaction failed to reach a conventional level of statistical significance, the result is essentially inconclusive. In the present study, we asked participants (psychology students) to rate the personality of two (imagined) typical representatives from different groups: psychology students at the same German university as the participants versus young adults in general. We chose these two groups because participants were members of both groups while arguably sharing more characteristics with members of the more narrow group (psychology students) than with young adults in general. In turn, if the level of assumed similarity is comparable for targets from both groups, this would speak against spurious similarity as a primary driver of the assumed similarity correlations. If, by contrast, spurious similarity is responsible for assumed similarity, raters' self-ratings should be more closely linked to their observer report of a group member from the narrow group (i.e., another psychology student). Thus, the design allowed for a straightforward test of (true) assumed similarity vis-à-vis spurious similarity.

At the same time, the experimental design also allowed for a still stricter test of the lack-of-information account: Given that judges have no external information available at all (i.e., they were only asked to imagine the targets), differences in trait predictability can no longer account for trait-specific differences in assumed similarity. In other words, whereas photos may arguably convey some, albeit limited, information about the targets - and probably for some traits even more than for others - raters now only received entirely unspecific information about a target's group membership. The lack-of-information account would thus predict that assumed similarity should occur for several traits and not only for those bearing a strong link to values. 


\section{Method}

\section{Procedure and materials}

The study was conducted as a web-based experiment. After providing informed consent and demographic information (including questions on participants' field of study and their university), participants completed the Self-Report Form of the German HEXACO-60 (all $\alpha \geq$ .76; for details, see Table O6 in the OSF materials). Thereafter, participants were asked to rate the personality of two to-be-imagined target persons, a typical psychology student from the same German university and a typical young adult. Participants were asked to imagine the target persons as vividly as possible. The order of the two observer reports was counterbalanced across participants, and ratings were collected using the Observer Report Form of the HEXACO-60 (all $\alpha \geq .60$ for the student rating and $\alpha \geq .65$ for the adult rating; Table 06). To ensure that participants were aware of the specific target to be judged subsequently, participants had to correctly answer a control question asking them to indicate the specific target for the following task before beginning with the rating. Following the two observer ratings, participants finally answered some questions assessing their identification with the typical psychology student and the typical young adult (adapted from Doosje, Ellemers, \& Spears, 1995), using a six-point Likert-type scale ranging from 1 = "completely disagree" to $6=$ "completely agree". An example item is "I feel connected with [other young adults] / [psychology students at this university]" (for a comprehensive list of items, see the additional materials provided on the OSF). These questions served as a manipulation check to ensure that participants indeed perceived stronger commonalities with the typical psychology student as compared to the young adult. As a compensation for participation, participants could receive course credit and feedback on their individual personality profile.

\section{Participants}

To determine the required sample size, we again used an a priori power analysis (G*Power; Faul et al., 2009) with similar specifications as in Study 4 (i.e., small to medium- 
sized effect of a single regression coefficient in a linear multiple regression analysis, $f^{2}=.09$, with $k=3$ predictors and $\alpha=.05$ ). Importantly, to provide more conclusive results especially for null effects - we aimed at obtaining high statistical power of $1-\beta=.95$, resulting in a required sample size of $N=122$. However, again note that the actual power obtained with said specifications was arguably larger given that we tested the interaction effect under scrutiny in a multilevel analysis to fully exploit the repeated measurements provided by each participant. In other words, we were actually able to detect a smaller effect size as the one specified for said interaction with a similar (high) level of statistical power.

Corresponding to the power analysis, we recruited $N=137$ psychology students at a German university who completed all tasks. ${ }^{11}$ However, $n=14$ participants had to be excluded given that their responses either indicated careless responding (i.e., average time per HEXACO item < 2sec) or showed extremely low variance within the observer reports (i.e., $S D<0.3$ across items); another participant indicated having repeatedly participated and was thus also excluded from the analyses. The final sample comprised $N=122$ participants, of whom $n=106(86.9 \%)$ were female. Participants were aged between 18 and 43 years $(M=$ $21.9, S D=4.5$ ), and all were psychology students at the same German university (as required by our design).

\section{Results and discussion}

To check whether our manipulation of group membership was successful - meaning that participants felt higher commonalities with a typical psychology student from their own university than with a typical young adult - we first compared participants' identification with these two groups using a paired-samples $t$-test. Confirming that the manipulation worked as intended, participants indicated a significantly stronger identification with typical psychology

${ }^{11}$ Additionally, $n=40$ participants started the study but dropped out during participation before completing all tasks. 
students $(M=4.32, S D=0.91)$ as compared to typical young adults $(M=3.99, S D=1.03)$, $t(121)=3.54, p<.001$, reflecting a small to medium-sized effect of Cohen's $d=0.32$.

Assumed similarity was again operationalized as the correlation between raters' selfreports and their observer reports of the targets' personality, separated for the two types of targets. However, note that with the specific design used, it was impossible to account for actual similarity given that the targets were no "real" (but imagined) others. As summarized in Table 7 (for descriptive statistics, internal consistencies, and inter-correlations between all variables, see Table O6 in the OSF materials), assumed similarity was again largest for Honesty-Humility, revealing highly similar, medium-sized correlations for both target persons alike (i.e., $r=.31, p<.001$ and $r=.36, p<.001$, for typical psychology student and typical young adult, respectively). Moreover, aside from Honesty-Humility, only Openness yielded significant assumed similarity for both groups of targets, with a slightly larger correlation for the typical young adult $(r=.29, p<.001)$ as compared to the typical psychology student $(r=$ $.18, p=.023)$. Importantly, for both trait dimensions, the pattern of assumed similarity correlations was opposite to what would be expected under spurious similarity: Assumed similarity was descriptively larger for the rating of the typical young adult (the wide group) than for the rating of the typical psychology student (the narrow group). Among the remaining dimensions, additional effects occurred for Emotionality and Agreeableness, but only for the judgment of the typical psychology student $(r=.16, p=.037$ and $r=.24, p=.003$, respectively), not for the judgment of the young adult ( $r=-.09$ and $r=-.05$, respectively).

To test whether the apparent differences in assumed similarity correlations across targets were statistically significant - and thus whether assumed similarity correlations were inflated by spurious similarity - we resorted to the same multilevel regression approach as in Study 4 (using lme4 in R; Bates et al., 2014). That is, we predicted raters' observer reports of the targets' personality by raters' self-reports, the type of target (dummy-coded; $0=$ young adult, $1=$ psychology student), and their interaction. All predictor variables were centered on 
the sample mean. However, we refrained from testing the differences in correlations for Honesty-Humility and Openness given that the pattern of correlations in itself already contradicted spurious similarity. By contrast, the models for Emotionality and Agreeableness yielded significant interactions between raters' self-reports and the type of target, in the direction conforming to spurious similarity, $B=0.19, p=.012$ for Emotionality and $B=0.19$, $p=.023$ for Agreeableness, respectively. In turn, reflecting the pattern of zero-order correlations, neither for Emotionality, nor for Agreeableness a meaningful level of assumed similarity was apparent across targets, as evidenced by non-significant main effects of raters' self-reports in both regression models, $B=0.03, p=.286$ and $B=0.06, p=.065$, respectively.

Overall, Study 5 provided further evidence that assumed similarity is largely restricted to Honesty-Humility and Openness: Even with extremely limited information available about a target person, individuals' self-reports were only linked to their observer reports for these two traits. Importantly, the finding that the level of assumed similarity was highly similar across targets suggests that the correlations for Honesty-Humility and Openness in particular cannot be fully accounted for by spurious similarity. In fact, for these two traits, the small differences in assumed similarity observed were in the opposite direction as predicted by spurious similarity. Thus, if anything, assumed similarity was larger for the target from the wider group than for the target from the narrow group.

By comparison, the findings suggested that for other traits assumed similarity might indeed be inflated by spurious similarity. Specifically, we found significant assumed similarity correlations for Emotionality and Agreeableness if and only if the target was a member of the narrow group (another psychology student). However, it should be stressed that although this finding is in principle compatible with spurious similarity, it can also be accounted for by true assumed similarity: Judges might have selectively consulted their own personality when rating a target for whom they considered their own trait level diagnostic - in our case, when judging the typical psychology student. Admittedly, our design cannot clearly 
disentangle these explanations. Moreover, it might be the case that judges imagined someone they actually knew given that the task to imagine a "typical other" may have been difficult for (some) participants. In combination with the prior finding that assumed similarity is stronger among well-acquainted dyads (e.g., Kenny, 1994; Lee et al., 2009; Selfhout et al., 2009), this might also explain the comparably high level of assumed similarity observed in this study. In any case though, the results were again clearly incompatible with the idea that assumed similarity might reflect a lack-of-information effect: Although judges had hardly any information available about the target persons (and certainly less than in previous designs), assumed similarity was again mostly restricted to Honesty-Humility and Openness (and no larger than observed for judgments of well-acquainted others; Table 1).

\section{Study 6}

Although the findings from our previous studies are largely in line with the value account, the evidence presented so far is, admittedly, quite indirect. In essence, support is generated from the observation that assumed similarity is essentially restricted to HonestyHumility and (albeit less robustly so) Openness, the two HEXACO dimensions that are most strongly linked to personal values. However, whether this particular link to values is indeed responsible for the proneness of these traits to reveal assumed similarity is an open question. In Study 6, we therefore aimed at providing an initial, more direct test of a potential mechanism underlying the value account. Specifically, the value account predicts that individuals will particularly rate others to be similar to themselves on Honesty-Humility and Openness because "these two personality factors serve as a dispositional basis for individuals' value systems, and thereby exert important effects on one's identity" (Lee et al., 2009, p. 471). In Study 6, we tested this assumption of the value account that the personal relevance ascribed to Honesty-Humility and Openness exceeds the personal relevance ascribed to the remaining HEXACO dimensions, which might be one plausible explanation for the particular susceptibility of these traits to assumed similarity. 


\section{Method}

\section{Procedure and materials}

The current study was conducted as part of a larger lab-based experiment and therefore embedded in a set of other unrelated tasks not pertinent to this investigation. At the beginning of the experiment, participants provided informed consent and demographic information. Thereafter, they worked on an unrelated memory task before starting with the rating task focused on herein. In the rating task, participants were presented with the 60 items from the Self-Report Form of the HEXACO-60 and asked to rate each item with regard to how important they perceived the corresponding statement to describe their own personality. That is, participants were specifically instructed that they should not rate the items with regard to how much they agreed or disagreed with each statement but rather that they should imagine describing themselves to another person and state how personally relevant each item would be for such a self-description. Participants' responses were collected on a five-point Likert-type scale ranging from $1=$ "not important at all" to 5 = "very important". After having completed the rating, participants worked on other unrelated tasks. Participants received compensation according to their performance and behavior in the unrelated tasks.

\section{Participants}

Given that the main aim of Study 6 was to test potential differences in the self-relevance ascribed to the different HEXACO dimensions, we based our a priori sample size considerations on a one-sample $t$-test (i.e., a pair-wise comparison of two dimensions). Specifically, we aimed at being able to detect a small to medium-sized mean level difference (Cohen's $d=0.35$ ) with a conventional alpha level of $\alpha=.05$ and satisfactory power of $1-\beta=$ .80 , which yielded a required sample size of $N=67$ (G*Power; Faul et al., 2009). Correspondingly, we recruited $N=71$ participants from a local participant pool at a German university. However, one participant had to be excluded due to providing incomplete data for the self-relevance rating, thus resulting in a final sample size of $N=70$. The majority (92.9\%) 
of participants were female, they were aged between 18 and 30 years $(M=21.5, S D=2.3)$, and almost all participants were students from different fields of study.

\section{Results and discussion}

Table 8 provides the means and standard deviations of the HEXACO self-relevance ratings as well as test statistics from one-sample $t$-tests for mean level comparisons against Honesty-Humility and Openness (for inter-correlations between ratings, see Table O7 in the OSF materials). In line with the idea that especially those traits that relate most strongly to values are particularly important to one's identity, personal relevance ratings were overall highest for items measuring Honesty-Humility, followed by items measuring Openness. Correspondingly, mean level comparisons revealed that the perceived self-relevance of Honesty-Humility was significantly larger than for all other trait dimensions, except for Openness. For Openness, in turn, results revealed a significantly larger mean level in comparison to Emotionality and Agreeableness, whereas the comparison to Extraversion and Conscientiousness failed to reach statistical significance and only yielded small effects (Cohen's $d=.09$ and .15 , respectively).

Overall, the results of Study 6 provide initial evidence for self-relevance as a potential mechanism underlying the value-related assumed similarity effects: Overall, individuals assigned the highest personal relevance to Honesty-Humility and Openness (albeit the selfrelevance ascribed to Openness was only descriptively larger than the one ascribed to Extraversion and Conscientiousness). The pattern of self-relevance assigned to the different HEXACO traits thus nicely mirrors the pattern of assumed similarity observed in Studies 1-5: The strongest effects of assumed similarity consistently occurred for Honesty-Humility whereas for Openness, effects were somewhat smaller and statistically less robust. For the remaining dimensions, in turn, there was no consistent evidence for assumed similarity. However, it should be noted that the way we assessed personal relevance implied that personally relevant traits are also those that individuals are willing to disclose to others in a 
self-description. Future research might therefore validate the specific measure of selfrelevance used and test whether the results can be replicated when self-relevance is operationalized independent of self-presentation. Nonetheless, the results imply that personal relevance ascribed to different trait dimensions indeed represents a plausible explanation for the trait-specific effects of assumed similarity as proposed by the value account.

\section{Study 7}

Study 6 showed that the personal relevance assigned to the HEXACO traits mirrors the trait-specific effects of assumed similarity: On average, individuals judge others to be similar to themselves on those traits that are also rated as highly relevant to people's identities. Findings from Study 6 were thus again in line with the value account and provided initial evidence for a potential mechanism underlying the value-related, trait-specific effects of assumed similarity. However, a direct test of the core assumption of the value account - that is, that the specific (strong) link of Honesty-Humility and Openness to values makes these two trait dimensions particularly susceptible to assumed similarity - is still missing. Study 7 aimed to close this gap and to thereby provide a rigorous test of the value account. Specifically, we used a priming procedure to increase participants' salience to their own values and investigated whether the priming of personal values led to an increased level of assumed similarity, especially on Honesty-Humility and Openness as would be predicted by the value account.

\section{Method}

\section{Procedure and materials}

Study 7 again implemented a longitudinal design to separate the personality self-report from the observer ratings. That is, we again recruited participants from a local participant pool who had already completed an online pre-study assessing the Self-Report Form of the HEXACO-60 (all $\alpha \geq .65$; for details, see Table O8 in the OSF materials) and invited them to a (lab-based) study to collect observer ratings of different (unknown) target persons. 
Participants' responses from the two parts of the study were matched via self-generated, pseudonymous IDs.

In the lab, participants first provided informed consent and demographic information before they were randomly assigned to one of two experimental conditions: a no-priming condition or a priming condition. In the no-priming condition, we used the exact same procedure as in Study 4: Participants were presented with two target persons on photos (one male and one female, in counterbalanced order) and asked to rate the personality of these persons using the Observer Report Form of the HEXACO-60 (all $\alpha \geq .67$; Table O8). ${ }^{12}$ Targets were randomly selected from the same stimulus set as in Study 4 including 50 photos of students (31 female and 19 male) depicted in their usual outfit and in a spontaneous pose. In the priming condition, in turn, we used the revised version of the Portrait Values Questionnaire (PVQ5X; Schwartz et al., 2012) to prime individuals to their personal values, in accordance with prior research (Zhang et al., 2016). That is, participants first responded to the PVQ5X before judging the personality of the two target persons. The PVQ5X contains 57 items portraying another person's aspirations, goals, or wishes related to Schwartz's ten basic personal values. Participants were asked to rate how similar they perceived the portrayed person to themselves using a six-point Likert-type scale ranging from $1=$ "not at all similar to me" to $6=$ "very similar to me". As a compensation for participation, participants received $10 €$ (approx. 11.60US\$ at the time of data collection).

\section{Participants}

We conducted an a priori power analysis using $\mathrm{G}^{*}$ Power (Faul et al., 2009) to determine the required sample size for our main test of the interaction between raters' self-reports and

${ }^{12}$ Collecting observer ratings for two target persons (one male and one female) allowed us to provide another test of spurious similarity by investigating whether assumed similarity is moderated by the congruence between rater and target sex (see Study 4). However, given that the main objective of Study 7 was to test the value account, we will focus on the effect of value priming on assumed similarity in what follows, but provide the results on the effect of (in)congruence between raters' and targets' sex in the OSF materials (Table O9; see also the discussion of Study 7 for a brief summary). 
value priming on raters' observer reports. Specifically, we aimed at detecting a small to medium-sized effect of a single regression coefficient in a multiple regression analysis $\left(f^{2}=\right.$ .09 ) including $k=3$ predictors with high power of $1-\beta=.90$ and one-tailed $\alpha=.05$, which resulted in a sample size of $N=97$. Correspondingly, we recruited $N=98$ participants comprising the final sample. The majority of participants were female $(81.6 \%)$, they were aged between 18 and 33 years $(M=22.2, S D=2.7)$, and all were students from diverse fields of study. Participants were equally distributed across experimental conditions (i.e., $n=49$ in both the no-priming and the priming condition).

\section{Results and discussion}

To determine the level of assumed similarity, we calculated the correlations between raters' self-report and their average observer report across the two targets. Similarly, actual similarity was calculated as the correlation between raters' self-report and the aggregated selfreport across the two targets. Across priming conditions, assumed similarity correlations were significant for Honesty-Humility $(r=.31, p<.001)$ and Agreeableness $(r=.21, p=.017)$. For Openness, in turn, the effect was only small in size and failed to reach statistical significance $(r=.10, p=.163)$. Actual similarity correlations, in turn, did not significantly differ from zero for any HEXACO dimension, ranging from $r=-.18$ for Agreeableness to $r=.17$ for Openness.

Determining the level of assumed similarity per condition further revealed that correlations for Honesty-Humility and Agreeableness were, descriptively, larger and only significant in the priming condition as compared to the no-priming condition (Table 9; for descriptive statistics, internal consistencies, and inter-correlations between all variables, see Table $\mathrm{O} 8$ in the OSF materials). To test whether these differences across conditions were significant, we used a multilevel regression analysis (lme4 in R; Bates et al., 2014), predicting raters' observer reports of targets' personality by raters' self-reports, a dummy variable coding the priming condition $(0=$ no-priming, $1=$ priming $)$, the interaction between self- 
reports and priming condition, and the targets' self-reports (to account for actual similarity). As before, all predictor variables were centered on the sample mean. For Honesty-Humility, the model revealed a significant main effect of raters' self-reports, $B=0.32, p<.001$, as well as a (one-tailed) significant interaction between raters' self-reports and the priming condition, $B=0.34, p=.046$. Thus, the level of assumed similarity was not only significant overall, but also significantly larger under value priming. For Agreeableness, in turn, raters' self-reports likewise yielded a significant main effect, $B=0.17, p=.020$, but a small and non-significant interaction with the priming condition, $B=0.19$, one-tailed $p=.132$. For the remaining HEXACO dimensions, including Openness, regression analyses indicated neither a significant level of assumed similarity, nor an interaction with value priming.

In summary, Study 7 again showed that assumed similarity is most consistently apparent for Honesty-Humility and further indicated that assumed similarity for this trait dimension even increased when raters were primed to their personal values. This implies that the assumed similarity effect for Honesty-Humility is indeed, at least in part, attributable to the strong link of this trait dimension to personal values. By contrast, results for Openness were not fully in line with the value account, as the level of assumed similarity was again small for this dimension, even when participants were primed to their personal values. This result once again demonstrates the comparably weak (and inconsistent) assumed similarity effect for Openness when rating strangers. Likewise, the finding that Agreeableness showed a meaningful level of assumed similarity once raters were primed to their personal values is not strongly implied by the value account. Finally, note that the results on assumed similarity separated for same sex and opposite sex targets (see Table O9 in the OSF materials) closely mirrored the findings from Study 4 in that they again implied that spurious similarity might contribute to assumed similarity correlations, but mostly on other traits than HonestyHumility and Openness. 
Although Study 7 provides support for the main proposition of the value account that a strong link to values makes certain traits particularly susceptible to assumed similarity, the potential mechanisms underlying this effect are still partially unclear. As outlined above, those traits that are closely tied to values may be particularly relevant to one's identity and therefore be prone to assumed similarity. In other words, one may want others to be like oneself especially on those traits that personally matter most. By implication, it may not be the particular link of Honesty-Humility and Openness to values per se that drives the consistent evidence of assumed similarity for these traits, but rather their high personal relevance (see Study 6) due to their strong relation to values. Following this logic, one may derive the hypothesis that any trait should reveal assumed similarity effects once the trait bears high personal relevance to an individual. In our final Studies 8 and 9, we aimed to provide direct tests of this potential "self-relevance mechanism" underlying the value account of assumed similarity. To begin with, in Study 8, we applied a within-subject logic and tested the hypothesis that the individually ascribed self-relevance of a trait moderates the strength of assumed similarity, in the sense that the higher the personal relevance a person assigns to a trait, the stronger should be the link between the person's self- and observer ratings on that trait.

\section{Method}

\section{Procedure and materials}

The study design, hypotheses, and analyses were pre-registered (https://aspredicted.org/tx8sj.pdf). The procedure closely followed the procedure of Studies 4 and 7. That is, participants were again recruited from a local participant pool at a German university and invited to take part in a (lab-based) study. To separate the personality selfreport from the observer ratings in time, we aimed to exclusively recruit participants who had already completed an online pre-study assessing the Self-Report Form of the HEXACO-60. However, given that we did not obtain the required (and pre-registered) sample size using this 
recruitment strategy, we additionally recruited participants for whom self-reports were not yet available and asked these participants to complete the HEXACO-60 prior to the remaining tasks in the lab (all $\alpha \geq .72$; for details, see Table O10 in the OSF materials).

In the lab session, all participants first provided informed consent and demographic information. In those sessions recruiting participants who had not yet completed the HEXACO self-rating, participants next worked on the Self-Report Form of the HEXACO-60. Then, in all sessions, participants were asked to rate the self-relevance of the six HEXACO dimensions using 30 bipolar adjective scales. Specifically, for each HEXACO dimension, we used five bipolar adjective scales - one capturing each of the four HEXACO-PI-R facets and one capturing the overall HEXACO factor (for specifics, see the additional materials on the OSF). For example, self-relevance ratings on Honesty-Humility were assessed by means of the following five adjective scales: sincere - sly (Sincerity facet), fair-minded - unfair (Fairness facet), unassuming - greedy (Greed Avoidance facet), modest - pretentious (Modesty facet), and honest - dishonest (Honesty-Humility factor). Participants were asked to rate each adjective pair with regard to how relevant they considered the described characteristics for their own personality or identity, respectively, using a five-point Likerttype scale ranging from $1=$ "not important at all" to $5=$ "very important". It was emphasized that participants ought not to rate the extent to which a certain adjective may describe them, but only how relevant they considered the underlying characteristic for their personality/identity - independent of where they might place themselves on the respective dimension. To obtain a single self-relevance score for each dimension, we aggregated the five ratings per dimension (all $\alpha \geq .61$, except for Emotionality with $\alpha=.50$; see Table 11 ). In general, note that we relied on this adjective-based assessment of self-relevance in Study 8 to prevent that participants had to complete the HEXACO-60 items several times in a row with different task instructions (which would have likely caused confusion and, most likely, some extent of consistent responding). 
Finally, as in Studies 4 and 7, participants were presented with two target persons on photos (one male and one female, in counterbalanced order) and asked to rate the personality of these persons using the Observer Report Form of the HEXACO-60 (all $\alpha \geq .70$, except for the observer rating of the female target on Emotionality with $\alpha=.57$; Table O10). Targets were randomly selected from the same stimulus set as before, including 50 photographs of students (31 female and 19 male) depicted in their usual outfit and in a spontaneous pose. In turn, collecting two observer reports allowed us to again test the potential influence of spurious similarity by investigating whether assumed similarity is moderated by the congruence between rater and target sex; we report these results in the OSF materials (Table O11) given that they are beyond the scope of the present study. As a compensation, participants received $4 €$ (approx. 4.70US\$) if they had already provided the self-rating in the online pre-study (which was incentivized independently) and $6 €$ (approx. 7.00US\$) if they provided the self-rating in the lab session.

\section{Participants}

To determine the required sample size, we conducted an a priori power analysis (see pre-registration) using G*Power (Faul et al., 2009). Given that straightforward power analyses are not available for multilevel regression analyses - which, however, represent the most adequate framework to test our hypothesis (see below) - we used a standard multiple regression analysis as an approximation. Specifically, we aimed to detect a small to mediumsized effect of a single regression coefficient $\left(f^{2}=.09\right)$ in a model predicting raters' average observer report on a given HEXACO trait (mean rating across the two target persons) by means of raters' self-report on that trait, the personal relevance assigned to that trait, the interaction between self-report and personal relevance, and targets' self-report on that trait. The single regression coefficient under scrutiny referred to the interaction between raters' self-report and personal relevance. Specifying $\alpha=.05$ and striving for at least satisfactory power of $1-\beta=.80$, this revealed a minimum required sample size of $N=90$ participants. 
Taking this as a lower bound estimate, we recruited $N=112$ participants in total. However, three participants had to be excluded because their pseudonymous IDs provided in the lab study could not be uniquely matched to the data from the online pre-study. The final sample thus comprised $N=109$ participants ( 87 female), aged between 18 and 45 years $(M=$ 22.9, $S D=3.4$ ). All participants were students from diverse fields of study. The majority of participants $(n=68)$ had already provided the personality self-report in the online pre-study.

\section{Results and discussion}

Table 10 summarizes the overall level of assumed similarity for the six HEXACO dimensions across the two target persons (i.e., correlations between raters' self-report and their average observer report; see Study 7) as well as the overall level of actual similarity (i.e., correlations between raters' self-report and the average self-reports of targets; for descriptive statistics, internal consistencies, and inter-correlations between all variables, see Table O10 in the OSF materials). As is apparent, Honesty-Humility again showed the highest level of assumed similarity $(r=.31, p<.001)$. Surprisingly, however, this time it was followed by Emotionality which likewise revealed a substantial assumed similarity correlation across targets $(r=.25, p=.004)$. Openness, in turn, did not show a meaningful level of assumed similarity $(r=-.03)$, nor did any of the remaining HEXACO dimensions (all $r \leq .11$ ). This pattern of assumed similarity remained the same once taking actual similarity between raters and targets into account (partial correlations in parentheses in Table 10) - corresponding to the fact that actual similarity correlations were negligible for all traits $(-.09 \leq r \leq .05$; Table $10)$.

Table 11 further shows the descriptive statistics and intercorrelations for the selfrelevance ratings of the HEXACO dimensions. Replicating the results from Study 6, the highest personal relevance was again ascribed to characteristics related to Honesty-Humility. By contrast, however, adjectives associated with Openness were, as compared to the other HEXACO dimensions, not perceived as being particularly relevant for one's 
personality/identity. Strikingly, self-relevance ratings were strongly intercorrelated, revealing an average correlation of $\bar{r}=.44$ and a high internal consistency across all 30 adjective pairs of Cronbach's $\alpha=.90$.

To test whether the individually assigned self-relevance of a trait indeed moderates the level of assumed similarity - in the sense that higher self-relevance may be associated with a stronger link between self- and observer ratings on the trait - we used a multilevel regression analysis (lme4 in R; Bates et al., 2014) predicting raters' observer reports of targets' personality on the six HEXACO dimensions (i.e., 12 ratings in total) by means of raters' selfreports, the self-relevance ascribed to a respective trait, the interaction between the selfreports and self-relevance, and targets' self-reports (see pre-registration). All predictor variables were centered on the sample mean. Given that we were specifically interested in testing whether the self-relevance of any given trait may affect the strength of assumed similarity on that trait, we essentially neglected information on the specific trait dimension to which the ratings pertained in the regression model but simply tested whether self-relevance moderated the link between self-ratings and observer ratings in general. Contrary to this hypothesis, however, there was no significant interaction between self-relevance and selfreports in predicting observer reports, $B=-0.002, p=.482$ (one-tailed), but only significant main effects of raters' self-reports, $B=0.07, p=.010$ (one-tailed), and targets' self-reports, $B$ $=0.13, p<.001-$ mirroring the overall level of assumed similarity across traits as well as a meaningful level of self-observer agreement. In turn, no main effect emerged for selfrelevance, $B=-0.03, p=.201$.

Taken together, Study 8 once again replicated the consistent assumed similarity effect for Honesty-Humility - and the less consistent effect for Openness. Moreover, there was a meaningful level of assumed similarity on Emotionality which is, however, arguably attributable to spurious similarity given that the effect was only apparent for the rating of the same-sex target $(r=.27, p=.002)$, but not for the rating of the opposite-sex target $(r=.00, p$ 
$=.484$; see Table O11). More importantly, although the self-relevance ratings did mirror the finding from Study 6 that Honesty-Humility was the most relevant trait, there was no reliable evidence for the idea that assumed similarity may be driven by the individually ascribed selfrelevance of a trait. That is, the hypothesized moderating effect of self-relevance on the link between self-reports and observer reports could not be confirmed at the within-subject level.

One potential explanation for this may be seen in the striking finding that the selfrelevance ratings revealed very high internal consistency across traits and were, in turn, strongly interrelated. This is particularly surprising given that self-relevance ratings in Study 6 - which were based on the HEXACO-60 items - were not related at all (i.e., $\bar{r}=.01$; see Table O7). We suspect that the high intercorrelations of the adjective-based self-relevance ratings in the current study are due to the high evaluativeness of the adjectives which are arguably much more evaluative than items of a personality inventory such as the HEXACO-PI-R. It is therefore conceivable that the adjective-based self-relevance ratings largely reflect (common) influences of social desirability. In line with this reasoning, Honesty-Humility and Extraversion - the two scales that received the highest "self-relevance" ratings in the present study - have indeed been found to be the two most socially desirable HEXACO dimensions (De Vries, Realo, \& Allik, 2016; see Footnote 16 below). Overall, one may therefore doubt whether the moderator variable that is vital to the intended hypothesis test adequately reflected the critical construct of trait-specific self-relevance.

\section{Study 9}

Study 9 sought to provide another direct test of the potential self-relevance mechanism underlying assumed similarity. Specifically, we relied on a priming procedure to experimentally increase the self-relevance of a given trait (between-subjects) and tested whether assumed similarity becomes stronger as a consequence of this self-relevance priming. As such, Study 9 allowed overcoming the limitations associated with the self-relevance assessment and exclusive reliance on participants' self-reports in Study 8, arguably providing 
a more direct and conclusive test of the self-relevance hypothesis based on an experimental approach. Unlike Study 8, we thus applied a between-subject logic in Study 9, testing whether (manipulated) differences in the self-relevance of traits across individuals moderate assumed similarity. As an add-on, we aimed to test the robustness of the assumed similarity effect among strangers once raters and targets are less similar to each other. Specifically, in all our prior studies, raters and targets were somewhat similar in age, cultural, and educational background because they were all students. In Study 9, we recruited a more diverse sample of raters and also used a more diverse stimulus set containing photographs of targets of different age and cultural background/ethnicity (e.g., Ott-Holland, Huang, Ryan, Elizondo, \& Wadlington, 2014; Rogers \& Biesanz, 2014).

\section{Methods}

\section{Procedure and materials}

The experimental design, hypotheses, and analyses were again pre-registered (https://aspredicted.org/d5fs6.pdf). The study was conducted as a web-based experiment. To allow for recruitment of a large and diverse sample, participants (raters) were recruited via a professional panel provider in Germany. To again implement a longitudinal design separating the personality self-reports from the observer ratings, we specifically sampled among participants who had taken part in a prior large-scale study including assessment of selfreported personality using the HEXACO-60 $(\mathrm{T} 1-N=2,431)$.

In the current study, participants first provided informed consent and demographic information. Thereafter, they were randomly assigned to one of six priming conditions, with each condition priming the self-relevance of one particular HEXACO dimension. Participants received a detailed description of the respective (to-be-primed) personality trait, together with the information that said trait "is one of the basic dimensions of human personality" (see OSF materials for further details on the instructions). Participants were then asked to think about how they would assess themselves on the described characteristic, that is, whether they had a 
low, moderate, or high trait level. Importantly, participants were not asked to provide a selfassessment, but only to think carefully about their individual trait level and to confirm once having done so.

Following the self-relevance priming, participants were presented with a half-body photograph of an unknown target person and asked to rate this target using the Observer Report Form of the HEXACO-60 (all $\alpha \geq .67$; for details, see Table O12 in the OSF materials). ${ }^{13}$ The photos were taken from a stock photo database, and they depicted a person in front of a neutral (white) background in spontaneous pose. The stimulus set contained 60 photographs in total (30 female and 30 male targets), one of which was randomly presented to each participant. In generating the stimulus set, we took particular care to cover a broad age range among targets and to also include non-Caucasian targets. This allowed us to critically test whether the assumed similarity effects observed in our prior studies will replicate once rater and target persons are less similar in terms of basic demographic characteristics. ${ }^{14}$

\section{Participants}

To determine the required sample size, we conducted an a priori power analysis using G*Power (Faul et al., 2009), and we relied on a linear regression analysis as an approximation for the multilevel regression used (see pre-registration). Specifically, we aimed to detect a small to medium-sized effect of a single regression coefficient $\left(f^{2}=.09\right)$ in a multiple regression predicting a rater's observer report on a given HEXACO trait by means of the rater's self-report on that trait, a dummy variable reflecting whether or not the self-relevance of this trait was primed, and the interaction between self-report and self-relevance priming. The latter interaction effect was the regression coefficient under scrutiny. Specifying $\alpha=.05$

\footnotetext{
${ }^{13}$ To detect careless responding, we added an attention check item to the observer rating asking participants to simply select the response option "completely agree". Participants who failed to correctly respond to the attention check were excluded from the analyses (see pre-registration).

${ }^{14} \mathrm{~A}$ drawback of this procedure is that we were no longer able to control for actual similarity between raters and targets as there were no personality self-reports of the target persons available. However, given that the level of actual similarity was overall negligible in all our prior studies in which raters and targets were arguably much more similar than in the current study (they were all students of roughly the same age), it is reasonable to assume that the results remain the same once taking actual similarity into account.
} 
and striving for high statistical power of $1-\beta=.95$, this resulted in a required sample size of $N$ $=175$ participants for each comparison of a primed versus non-primed trait, thus implying around 88 participants in each priming condition. We therefore decided to strive for a total sample size of $N=600$ participants, with $n=100$ in each of the six priming conditions.

Corresponding to these calculations, we recruited $N=716$ participants who completed all tasks (out of 778 who started the study). However, 112 participants had to be excluded from the analyses based on the following (pre-registered) criteria: 70 participants failed the attention check (see Footnote 13), 33 required less than $2 \mathrm{sec}$ on average per item of the HEXACO-60 observer report, and 9 showed extremely low variance among the observer report items (i.e., $S D<0.3$ across items). The final sample thus comprised $N=604$ participants. Corresponding to our recruitment strategy, the sample was much more diverse than is typically obtained with student samples, with participants being almost equally distributed across the sexes (i.e., $47.2 \%$ female), spanning a broad age range of 19 to 67 years $(M=45.0, S D=12.5)$, and having diverse educational backgrounds. The majority of participants $(67.9 \%)$ were in employment; only $7.3 \%$ were students.

\section{Results and discussion}

Table 12 summarizes the assumed similarity correlations across priming conditions as well as separately for primed versus non-primed traits (for descriptive statistics, internal consistencies, and inter-correlations between all variables, see Table $\mathrm{O} 12$ in the OSF materials). As is apparent, the strongest assumed similarity effect across conditions again emerged for Honesty-Humility $(r=.28, p<.001)$, somewhat surprisingly followed by Agreeableness $(r=.27, p<.001)$ and, less surprisingly, Openness $(r=.17, p<.001)$. For the remaining HEXACO dimensions, assumed similarity correlations were maximally small in size. More importantly, and in line with the self-relevance hypothesis, four of the six assumed similarity correlations increased descriptively once the respective trait had been primed. In turn, only the effect of Agreeableness decreased given self-relevance priming, whereas the 
effect of Honesty-Humility remained essentially the same. Correspondingly, the overall correlation between self-reports and observer reports across HEXACO dimensions was $r=$ .22 for primed traits and $r=.16$ for non-primed traits.

To test this effect of self-relevance priming on assumed similarity statistically, we ran a multilevel regression (lme4 in R; Bates et al., 2014) predicting raters' observer reports of the targets' personality on the six HEXACO dimensions by means of raters' self-reports, selfrelevance priming (dummy-coded; $0=$ not primed, $1=$ primed), and their interaction. As before, all predictor variables were centered on the sample mean. Supporting the descriptive picture and the self-relevance hypothesis, there was a significant, positive interaction between self-ratings and self-relevance priming in predicting observer ratings, $B=0.08, p=.029$ (onetailed). Moreover, the regression analysis revealed a significant main effect of self-reports, $B$ $=0.15, p<.001-$ reflecting the overall assumed similarity effect - but no main effect of selfrelevance priming, $B=0.03, p=.251 .^{15}$

Overall, Study 9 once again provided evidence for assumed similarity on HonestyHumility and, less strongly, Openness when judging strangers and extended the findings to ratings of more diverse and less similar target persons. More importantly, Study 9 yielded direct support for self-relevance as a potential mechanism behind assumed similarity in basic personality traits. The results thereby provide a reasonable explanation for the particular susceptibility of value-related traits to assumed similarity: Because traits that are strongly linked to values are highly relevant to one's identity (Study 6; see also Lee et al., 2009), individuals tend to particularly rate others as similar to themselves on these traits. The finding that self-relevance priming did not further increase assumed similarity for Honesty-Humility is also plausible in light of the assumption that the personal relevance of Honesty-Humility is already high a priori - thus explaining the consistently strongest assumed similarity found for

\footnotetext{
${ }^{15}$ In line with our pre-registration, we finally complemented this overall analysis by separate linear regression analyses for each of the six HEXACO dimensions. The results of these trait-specific regressions are available in the OSF materials (Table O13).
} 
Honesty-Humility across all studies. In turn, the finding that self-relevance priming strongly increased assumed similarity for Openness implies that the relevance of corresponding characteristics is not as high, a priori and in general, as for Honesty-Humility - thus providing a potential explanation for why the assumed similarity effect on Openness when rating strangers is less consistent overall.

\section{General Discussion}

In many day-to-day encounters, individuals need to form judgments about other people's characteristics. Various studies to date have shown that individuals' self-descriptions are linked to such judgments about others' personality, in the sense that judges' self-reports typically show a certain level of similarity to how they rate others. To account for this phenomenon termed assumed similarity, several accounts have been proposed in prior research. However, direct empirical tests of these accounts are scarce and comparisons across different accounts are missing entirely. In a set of nine studies, we aimed at closing this gap by investigating assumed similarity in personality judgments of basic personality traits (i.e., the HEXACO dimensions), using specific experimental tests and manipulations tackling the different theoretical accounts proposed. Thereby, the current work provides an enhanced understanding of why assumed similarity occurs in personality judgments.

A key finding of our studies - conceptually replicating and extending prior research - is that assumed similarity is indeed highly trait-specific. As is apparent in the right panel of Figure 1 (providing the sample size-weighted average correlations across all our studies assessing personality judgments, i.e., all but Study 6, $N=1,350$; Field, 2001; Hunter \& Schmidt, 1990), we consistently found the strongest assumed similarity effect for HonestyHumility, resulting in an average correlation of $\bar{r}=.30$ across studies and thus a mediumsized effect. Moreover, Openness yielded a significant assumed similarity correlation in some studies, albeit revealing a less consistent and weaker effect overall (meta-analytic $\bar{r}=.16$ ). Apart from these two traits, only Agreeableness showed a substantial meta-analytic effect size 
estimate across our studies $(\bar{r}=.15)$. However, it must be noted that this effect is almost exclusively driven by Study 9 which was the only study in which Agreeableness revealed a meaningful level of assumed similarity (unless primed; Study 6) and which, incidentally, made up almost half of the entire sample size (i.e., $N=604$ in Study 9 vs. $N=746$ in Studies 1-8, excl. Study 6). Correspondingly, the meta-analytic assumed similarity correlation for Agreeableness was only $\bar{r}=.06$ once excluding Study 9 .

For the remaining HEXACO dimensions, in turn, assumed similarity correlations were mostly negligible, with meta-analytic effect sizes ranging from $\bar{r}=.04$ for Extraversion to $\bar{r}=$ .06 for Emotionality (right panel in Figure 1). As such, our findings are generally well in line with prior evidence on assumed similarity of the HEXACO dimensions among acquainted others (Table 1 and middle panel in Figure 1) but extend these to personality judgments among strangers. In turn, effect sizes from ratings of strangers in our studies (excluding the roommate and fellow student rating in Study 1) were somewhat smaller than previously observed for judgments of acquainted others (i.e., $\bar{r}=.29$ vs. $\bar{r}=.48$ for Honesty-Humility and $\bar{r}=.14$ vs. $\bar{r}=.35$ for Openness), despite showing a highly similar (trait-specific) pattern overall.

Indeed, especially the consistent assumed similarity effect for Honesty-Humility has important implications for the understanding of social judgments as it suggests that individuals tend to ascribe more similar trait levels to others on fairness- and morality-related characteristics, even when these others are complete strangers. As has been noted elsewhere, "of the many impressions people form of themselves and others, impressions of moral character are likely among the most relevant and consequential" (Barranti, Carlson, \& Furr, 2016, p. 806). Thus, the fact that judgments about others on this class of traits are particularly linked to corresponding self-reports is a noteworthy finding. In any case, these results are highly compatible with meta-analytic evidence on social value orientation (i.e., the weights people assign to own and others' outcomes), which likewise shows that prosocial individuals 
expect others to be prosocial as well (Pletzer et al., 2018). More distally, our results are also compatible with organizational research on overt integrity tests which typically comprise some items asking participants to indicate how common they believe moral behavior to be among people, and overt integrity tests are, in turn, linked to individuals' self-reported Honesty-Humility levels (Marcus, Lee, \& Ashton, 2007).

\section{How to account for assumed similarity?}

As previously summarized, our studies demonstrated that, even among strangers, assumed similarity is first and foremost contingent on the to-be-judged traits. That is, we only found consistent evidence for assumed similarity on Honesty-Humility. Moreover, assumed similarity was apparent for Openness, albeit only in some of our studies and thus less robustly than for Honesty-Humility. Nonetheless, assumed similarity correlations for Openness were almost always larger than those observed for the remaining HEXACO traits. Thus, our findings are generally compatible with the idea that assumed similarity is closely tied to personal values. As suggested by Lee and colleagues (2009), “assumed similarity for Honesty-Humility and Openness to Experience reflects a tendency to overestimate one's similarity to persons with whom one has a close relationship, but only on those personality characteristics whose relevance to values gives them central importance to one's identity" (p. 460). The current results extend this reasoning to personality judgments among strangers and show that the value account provides a viable explanation for assumed similarity in personality judgments in general. This implies that individuals generally expect others to be similar to themselves on traits that are strongly linked to values, irrespective of whether they have a (close) relationship to these others or do not know them at all.

Moreover, our studies provide some initial and direct evidence on why traits with strong links to values may be more susceptible to assumed similarity: They bear a particularly high personal relevance. Specifically, Honesty-Humility and Openness were perceived as being most relevant for individuals' identity, notably in the exact same rank-order as the assumed 
similarity effects observed (i.e., Honesty-Humility > Openness; Study 6). In turn, experimentally priming the self-relevance of the HEXACO traits generally increased assumed similarity correlations across traits (Study 9). Overall, this corroborates the notion that assumed similarity on Honesty-Humility and Openness is (at least partly) driven by the generally high personal relevance inherent in these traits.

However, whether this logic also implies that intra-individual differences in the selfrelevance of traits may determine intra-individual differences in assumed similarity - in the sense that the higher the personal relevance a person assigns to a trait, the higher the correlation between the person's self-report and her observer reports on that trait - remains an open quest for future research. In other words, whereas Study 9 provided support for the idea that (experimentally manipulated) between-subject differences in personal relevance may serve as a driver of trait-specific effects of assumed similarity, the corresponding within-level test provided by Study 8 yielded only inconclusive evidence in this respect. However, this may also be due to limitations in the assessment of personal relevance using self-reports. In any case, it is thus unclear whether the proposed self-relevance mechanism indeed holds at both the between- and the within-subject level - although the mechanism would logically imply so. That is, the idea that Honesty-Humility and Openness are particularly susceptible to assumed similarity because they show strong links to values and therefore bear high personal relevance directly implies that the (individual-level) self-relevance of these traits contributes to the observed assumed similarity effects. Future research is needed to clarify whether this reasoning indeed applies. Nonetheless, our findings offer a reasonable explanation for the value-related, trait-specific nature of assumed similarity in personality judgments and thereby allow for theoretical refinement of the value account by a personal relevance mechanism.

Notably, this refinement of the value account to involve a self-relevance mechanism also provides a plausible explanation for the observation that assumed similarity for Openness was weaker overall and less robust than the effect for Honesty-Humility - a finding that 
cannot be accounted for by the original version of the value account: Openness-related characteristics might simply be of lower personal relevance. Specifically, Openness was rated to be (descriptively) less relevant to individuals' identity than Honesty-Humility (Study 6) and, in turn, self-relevance priming had a strong effect on assumed similarity for Openness, but not for Honesty-Humility (Study 9). This implies that the personal relevance of Openness is not as high a priori as the personal relevance of Honesty-Humility. In turn, individuals might consider it more important that others are similar to themselves on Honesty-Humility than on Openness - which might also be attributable to the particularly high evaluativeness and thus social desirability of characteristics related to Honesty-Humility (De Vries et al., 2016). ${ }^{16}$

Nonetheless, although the value account thus seems to apply to personality judgments among strangers as well, comparing the effect sizes in our studies with prior evidence on assumed similarity among acquainted others (Table 1 and Figure 1) suggests that individuals indeed ascribe higher similarity in traits that are strongly linked to values to individuals with whom they have a (close) relationship. One may speculate that in the case of acquaintances, individuals are additionally motivated to perceive similarity, that is, they want to specifically think that their acquaintances are similar to them on those traits bearing high personal relevance. In other words, it is reasonable to assume that individuals find it particularly important that close others (as compared to complete strangers) share characteristics that are vital to their identity. Indeed, this reasoning is also in line with recent evidence showing that singles describe their ideal partners to be particularly similar to themselves on Honesty-

${ }^{16}$ Using the Dutch version of the HEXACO-PI-R, De Vries et al. (2016) collected expert ratings of the evaluativeness (i.e., social desirability) of the HEXACO dimensions. These ratings suggest that content related to Honesty-Humility $(M=4.06, S D=0.44)$ is indeed much more evaluative than content related to Openness $(M=3.24, S D=0.29)$ or any other HEXACO dimension (i.e., Emotionality: $M=2.90, S D=$ 0.56; Extraversion: $M=3.75, S D=0.40$; Agreeableness: $M=3.57, S D=0.44$; Conscientiousness: $M=$ 3.62, $S D=0.41$ ). We thank Reinout De Vries for providing us with the raw data of the evaluativeness ratings as these were not reported in the corresponding article. 
Humility (meta-analytic $r=.73$ ) and Openness (meta-analytic $r=.69$; for the remaining HEXACO dimensions $r \leq .49$; Liu, Ludeke, Haubrich, Gondan, \& Zettler, 2018). However, whether the assumed similarity effect on these very (value-related) traits is actually attributable to a certain motivation to see others as similar to the self is an open question that needs to be addressed in future research. More generally speaking, although the strong relation to values - and the corresponding importance of related traits for one's identity provides a straightforward explanation for the trait-specific nature of assumed similarity, future research is needed to further illuminate the specific cognitive processes involved in assumed similarity judgments.

\section{How not to account for assumed similarity?}

Overall, our results are at odds with the idea that assumed similarity essentially reflects a lack-of-information effect. As mentioned above, the lack-of-information account proposes that assumed similarity should be stronger the less information raters have about a target because in such situations of limited information, raters might use their own trait level as an additional source of information to form a personality judgment. Contrary to this reasoning, however, assumed similarity was significantly lower when rating a complete stranger as compared to (well-)known others for Openness and comparable across different levels of acquaintanceship for Honesty-Humility (Study 1). Likewise, assumed similarity correlations

for judgments of strangers as observed in our studies were generally lower than those reported in prior research for judgments of acquainted others (Figure 1). These results imply that assumed similarity is larger whenever individuals have more rather than less information available about a target person and are thus incompatible with the lack-of-information account.

Moreover, the finding that assumed similarity was largely restricted to HonestyHumility and Openness can also not be accounted for by the lack-of-information account: Although raters had very limited information about the targets in general, self-reports only 
showed a positive link to observer reports when rating another's Honesty-Humility and (albeit less robustly) Openness. Indeed, one may argue that Honesty-Humility in particular is hardly predictable for observers, for instance because individuals are motivated to conceal their immoral behavior from others (Thielmann et al., 2017). However, for other HEXACO traits as well prior evidence suggests a limited number and validity of trait-relevant cues available at lower levels of acquaintance (Lee \& Ashton, 2017). As such, the rank-order of assumed similarity effects on the trait level is simply incompatible with the degree to which these traits are typically considered visible or predictable: Assumed similarity is not most pronounced for traits with low predictability or vice versa. Moreover, even when raters only received very unspecific information about a target person and were simply asked to imagine the person (Study 5), assumed similarity was still restricted to Honesty-Humility and Openness. Especially in such situations characterized by a lack of external information about another, individuals' own personality should have been a helpful source of information to form a personality judgment if lack of information was indeed the driving factor underlying assumed similarity. In consequence, assumed similarity should have been apparent for other traits than Honesty-Humility and Openness as well.

Moreover, it is important to note that the assumed similarity effects observed for Honesty-Humility and Openness are not attributable to actual, known, or spurious similarity (Paunonen \& Hong, 2013), but arguably reflect "true" assumed similarity. First, actual similarity between raters and targets was largely absent in our studies; correspondingly, results remained virtually the same when controlling for actual similarity in the analyses. Second, known similarity can, by definition, only affect personality judgments among acquainted others. Thus, our approach to primarily focus on personality judgments among strangers ruled out known similarity as a potential alternative explanation for the observed effects in the first place. Finally, our finding that assumed similarity correlations for HonestyHumility and Openness were highly similar across rater-target dyads sharing a certain group 
membership such as sex (Studies 4, 7, and 9) or educational setting (Study 5) contradicts that assumed similarity for these dimensions can be accounted for by spurious similarity, that is, inferring targets' traits from shared group membership. Interestingly, for other trait dimensions (e.g., Emotionality) our studies indeed revealed evidence for spurious similarity. This implies that, at least on some traits, assumed similarity correlations might be spuriously inflated when raters and targets share a certain group membership. However, spurious similarity cannot fully account for the trait-specific pattern of assumed similarity observed and cannot be the primary source of assumed similarity on those traits that show assumed similarity (relatively) consistently, that is, Honesty-Humility and Openness.

\section{Limitations}

Although our findings provide general support for trait-specific effects of assumed similarity in line with the value account and a self-relevance mechanism, some limitations should be acknowledged that we hope can be tackled by future research. First, we exclusively focused on assumed similarity of broad, basic traits. As mentioned above, assumed similarity has also been intensively studied for other characteristics such as attitudes (e.g., Holtz, 1997; Paunonen \& Kam, 2014), affective experiences (e.g., Beer et al., 2013; Papp et al., 2010; Watson et al., 2000; Weller \& Watson, 2009), and certain behaviors (e.g., Mathison, 1988; McDade-Montez et al., 2013). Future research is therefore needed to investigate whether assumed similarity on these characteristics can also be unraveled by the value account and/or high self-relevance of these characteristics or whether the processes involved in assumed similarity differ for different classes of characteristics.

Closely related, future research is needed to illuminate whether the trait-specific nature of assumed similarity is solely attributable to differences in self-relevance of traits or whether other, more specific features of value-related traits (such as their link to social attitudes; Boer \& Fischer, 2013) additionally contribute to the observed assumed similarity effects. Indeed, the finding that assumed similarity for Honesty-Humility increased when individuals were 
primed to their values in general (Study 7), but not when the self-relevance of HonestyHumility was primed (Study 9) implies that different aspects of value-related traits might jointly drive assumed similarity. To clarify this issue, future research may therefore study assumed similarity in other traits which bear high personal relevance but have no particularly strong link to values. By implication, such tests will provide further insights on whether the value account can be extended or even reduced to a "self-relevance account". We hope that the presented studies will encourage future research along these lines.

\section{Conclusion}

The studies presented herein demonstrate the trait-specific nature of assumed similarity and thereby strongly suggest that the best theoretical account currently available is the value account. Specifically, individuals only rated unknown others to be similar to themselves on those basic traits that are strongly linked to their own values, a finding that is most plausibly attributable to the high personal relevance of these traits for one's identity. Thus, assumed similarity does not merely result from a lack of information or spurious similarity, but arguably reflects the assumption that others share one's basic parts of one's identity, even if these others are complete strangers. 


\section{Acknowledgments}

Preparation of this manuscript was supported by Grants HI 1600/1-1 and HI 1600/1-2 from the German Research Foundation (DFG) to the second and Grants ZE 948/1-1 from the German Research Foundation (DFG) and CF16-0444 from the Carlsberg Foundation to the final author. In addition, we thank Julia Aden, Annika Bauer, Laura Callensee, Katja Demmer, Gesine Flötotto, Pauline Frick, Paulina Galow, Philipp Gellner, Lena Heck, Hanna Kettenhofen, Laura Kilian, Leonie Schindler, Phillip Seibt, Jennifer Siegert, Anna Specie, Eric Thanbichler, and Sarah Wünsche for their support in collecting the data for Study 1, 2, 3, and 5 . 


\section{References}

Albright, L., Kenny, D. A., \& Malloy, T. E. (1988). Consensus in personality judgments at zero acquaintance. Journal of Personality and Social Psychology, 55(3), 387-395. https://doi.org/10.1037/0022-3514.55.3.3

Anglim, J., Knowles, E. R. V, Dunlop, P. D., \& Marty, A. (2017). HEXACO personality and Schwartz's personal values: A facet-level analysis. Journal of Research in Personality, 68, 23-31. https://doi.org/10.1016/j.jrp.2017.04.002

Arndt, J., Greenberg, J., Solomon, S., Pyszczynski, T., \& Schimel, J. (1999). Creativity and terror management: Evidence that creative activity increases guilt and social projection following mortality salience. Journal of Personality and Social Psychology, 77(1), 1932. https://doi.org/10.1037/0022-3514.77.1.19

Ashton, M. C., \& Lee, K. (2007). Empirical, theoretical, and practical advantages of the HEXACO model of personality structure. Personality and Social Psychology Review, 11(2), 150-166. https://doi.org/10.1177/1088868306294907

Ashton, M. C., \& Lee, K. (2008). The prediction of Honesty-Humility-related criteria by the HEXACO and Five-Factor Models of personality. Journal of Research in Personality, 42(5), 1216-1228. https://doi.org/10.1016/j.jrp.2008.03.006

Ashton, M. C., \& Lee, K. (2009). The HEXACO-60: A short measure of the major dimensions of personality. Journal of Personality Assessment, 91(4), 340-345. https://doi.org/10.1080/00223890902935878

Ashton, M. C., \& Lee, K. (2018). How well do Big Five measures capture HEXACO scale variance? Journal of Personality Assessment. Advance online publication. https://doi.org/10.1080/00223891.2018.1448986

Ashton, M. C., Lee, K., \& De Vries, R. E. (2014). The HEXACO Honesty-Humility, Agreeableness, and Emotionality factors: A review of research and theory. Personality and Social Psychology Review, 18(2), 139-152. 
https://doi.org/10.1177/1088868314523838

Ashton, M. C., Lee, K., Perugini, M., Szarota, P., De Vries, R. E., Di Blas, L., ... De Raad, B. (2004). A six-factor structure of personality-descriptive adjectives: Solutions from psycholexical studies in seven languages. Journal of Personality and Social Psychology, 86(2), 356-366. https://doi.org/10.1037/0022-3514.86.2.356

Barranti, M., Carlson, E. N., \& Furr, R. M. (2016). Disagreement about moral character is linked to interpersonal costs. Social Psychological and Personality Science, 7(8), 806817. https://doi.org/10.1177/1948550616662127

Bates, D., Maechler, M., Bolker, B., \& Walker, S. (2014). lme4: Linear mixed-effects models using Eigen and S4. R package (Version 1.1-7). Retrieved from http://cran.rproject.org/web/packages/lme4/index.html

Beer, A., \& Watson, D. (2008). Personality judgment at zero acquaintance: Agreement, assumed similarity, and implicit simplicity. Journal of Personality Assessment, 90(3), 250-260. https://doi.org/10.1080/00223890701884970

Beer, A., Watson, D., \& McDade-Montez, E. (2013). Self-other agreement and assumed similarity in neuroticism, extraversion, and trait affect: Distinguishing the effects of form and content. Assessment, 20(6), 723-737. https://doi.org/10.1177/1073191113500521

Boer, D., \& Fischer, R. (2013). How and when do personal values guide our attitudes and sociality? Explaining cross-cultural variability in attitude-value linkages. Psychological Bulletin, 139(5), 1113-1147. https://doi.org/10.1037/a0031347

Brunswik, E. (1952). The conceptual framework of psychology. Oxford: University Chicago Press.

Cohen, J. (1988). Statistical power analysis for the behavioral sciences (rev. ed.). Hillsdale, NJ England: Lawrence Erlbaum Associates, Inc.

Cohen, T. R., Panter, A. T., Turan, N., Morse, L., \& Kim, Y. (2013). Agreement and similarity in self-other perceptions of moral character. Journal of Research in 
Personality, 47(6), 816-830. https://doi.org/10.1016/j.jrp.2013.08.009

Connelly, B. S., \& Ones, D. S. (2010). An other perspective on personality: Meta-analytic integration of observers' accuracy and predictive validity. Psychological Bulletin, 136(6), 1092-1122. https://doi.org/10.1037/a0021212

Connolly, J. J., Kavanagh, E. J., \& Viswesvaran, C. (2007). The convergent validity between self and observer ratings of personality: A meta-analytic review. International Journal of Selection and Assessment, 15(1), 110-117. https://doi.org/10.1111/j.14682389.2007.00371.x

Cosmides, L., \& Tooby, J. (1992). Cognitive adaptations for social exchange. In J. H. Barkow, L. Cosmides, \& J. Tooby (Eds.), The adapted mind: Evolutionary psychology and the generation of culture. (pp. 163-228). New York, NY, US: Oxford University Press.

Costa, P. T., \& McCrae, R. R. (1992). Revised NEO Personality Inventory (NEO-PI-R) and NEO Five-Factor Inventory (NEO-FFI) professional manual. Odessa, FL US: Psychological Assessment Resources.

Cronbach, L. J. (1955). Processes affecting scores on "understanding of others" and "assumed similarity." Psychological Bulletin, 52(3), 177-193. https://doi.org/10.1037/h0044919

De Vries, R. E. (2010). Lots of target variance: An update of SRM using the HEXACO Personality Inventory. European Journal of Personality, 24(3), 169-188. https://doi.org/10.1002/per.764

De Vries, R. E., Realo, A., \& Allik, J. (2016). Using personality item characteristics to predict single-item internal reliability, retest reliability, and self-other agreement. European Journal of Personality, 30(6), 618-636.

De Vries, R. E., \& van Kampen, D. (2010). The HEXACO and 5DPT models of personality: A comparison and their relationships with psychopathy, egoism, pretentiousness, immorality, and Machiavellianism. Journal of Personality Disorders, 24(2), 244-257. 
https://doi.org/10.1521/pedi.2010.24.2.244

Doosje, B., Ellemers, N., \& Spears, R. (1995). Perceived intragroup variability as a function of group status and identification. Journal of Experimental Social Psychology, 31(5), 410-436. https://doi.org/10.1006/jesp.1995.1018

Faul, F., Erdfelder, E., Buchner, A., \& Lang, A.-G. (2009). Statistical power analyses using G*Power 3.1: Tests for correlation and regression analyses. Behavior Research Methods, 41(4), 1149-1160. https://doi.org/10.3758/BRM.41.4.1149

Field, A. P. (2001). Meta-analysis of correlation coefficients: A Monte Carlo comparison of fixed- and random-effects methods. Psychological Methods, 6(2), 161-180.

Fischer, R., \& Boer, D. (2015). Motivational basis of personality traits: A meta-analysis of value-personality correlations. Journal of Personality, 83(5), 491-510.

Fiske, S. T. (1993). Social cognition and social perception. Annual Review of Psychology, 44(1), 155-194. https://doi.org/10.1146/annurev.ps.44.020193.001103

Funder, D. C., \& Dobroth, K. M. (1987). Differences between traits: Properties associated with interjudge agreement. Journal of Personality and Social Psychology, 52(2), 409418. https://doi.org/10.1037/0022-3514.52.2.409

Gonzaga, G. C., Campos, B., \& Bradbury, T. (2007). Similarity, convergence, and relationship satisfaction in dating and married couples. Journal of Personality and Social Psychology, 93(1), 34-48. https://doi.org/10.1037/0022-3514.93.1.34

Heck, D. W., Thielmann, I., Moshagen, M., \& Hilbig, B. E. (2018). Who lies? A large-scale reanalysis linking basic personality traits to unethical decision making. Judgment \& Decision Making, 13, 356-371.

Hilbig, B. E., \& Zettler, I. (2015). When the cat's away, some mice will play: A basic trait account of dishonest behavior. Journal of Research in Personality, 57, 72-88. https://doi.org/10.1016/j.jrp.2015.04.003

Hirschmüller, S., Egloff, B., Schmukle, S. C., Nestler, S., \& Back, M. D. (2015). Accurate 
judgments of neuroticism at zero acquaintance: A question of relevance. Journal of Personality, 83(2), 221-228. https://doi.org/10.1111/jopy.12097

Hoch, S. J. (1987). Perceived consensus and predictive accuracy: The pros and cons of projection. Journal of Personality and Social Psychology, 53(2), 221-234. https://doi.org/10.1037/0022-3514.53.2.221

Holmes, D. S. (1968). Dimensions of projection. Psychological Bulletin, 69(4), 248-268. https://doi.org/10.1037/h0025725

Holtz, R. (1997). Length of group membership, assumed similarity, and opinion certainty: The dividend for veteran members. Journal of Applied Social Psychology, 27(6), 539555. https://doi.org/10.1111/j.1559-1816.1997.tb00646.x

Human, L. J., \& Biesanz, J. C. (2011). Through the looking glass clearly: Accuracy and assumed similarity in well-adjusted individuals' first impressions. Journal of Personality and Social Psychology, 100(2), 349-364. https://doi.org/10.1037/a0021850

Hunter, J. E., \& Schmidt, F. L. (1990). Methods of meta-analysis: Correcting error and bias in research findings. Thousand Oaks, CA, US: Sage Publications, Inc.

Kenny, D. A. (1994). Interpersonal perception: A social relations analysis. New York, NY US: Guilford Press.

Kenny, D. A., Horner, C., Kashy, D. A., \& Chu, L. (1992). Consensus at zero acquaintance: Replication, behavioral cues, and stability. Journal of Personality and Social Psychology, 62(1), 88-97. https://doi.org/10.1037/0022-3514.62.1.88

Kenny, D. A., \& Kashy, D. A. (1994). Enhanced co-orientation in the perception of friends: A social relations analysis. Journal of Personality and Social Psychology, 67(6), 10241033. https://doi.org/10.1037/0022-3514.67.6.1024

Kenny, D. A., \& La Voie, L. (1984). The social relations model. Advances in Experimental Social Psychology, 18, 141-182.

Kenny, D. A., \& West, T. V. (2010). Similarity and agreement in self-and other perception: A 
meta-analysis. Personality and Social Psychology Review, 14(2), 196-213.

https://doi.org/10.1177/1088868309353414

Kleinlogel, E. P., Dietz, J., \& Antonakis, J. (2018). Lucky, competent, or a just a cheat?

Interactive effects of Honesty-Humility and moral cues on cheating behavior.

Personality and Social Psychology Bulletin, 44(2), 158-172.

https://doi.org/10.1177/0146167217733071

Krueger, J. I. (2007). From social projection to social behaviour. European Review of Social Psychology, 18, 1-35. https://doi.org/10.1080/10463280701284645

Lee, K., \& Ashton, M. C. (2006). Further assessment of the HEXACO Personality Inventory: Two new facet scales and an observer report form. Psychological Assessment, 18(2), 182-191. https://doi.org/10.1037/1040-3590.18.2.182

Lee, K., \& Ashton, M. C. (2016). Psychometric properties of the HEXACO-100. Assessment. Advance online publication. https://doi.org/10.1177/1073191116659134

Lee, K., \& Ashton, M. C. (2017). Acquaintanceship and self/observer agreement in personality judgment. Journal of Research in Personality, 70, 1-5. https://doi.org/10.1016/j.jrp.2017.05.001

Lee, K., Ashton, M. C., Morrison, D. L., Cordery, J., \& Dunlop, P. D. (2008). Predicting integrity with the HEXACO personality model: Use of self- and observer reports. Journal of Occupational and Organizational Psychology, 81(1), 147-167. https://doi.org/10.1348/096317907X195175

Lee, K., Ashton, M. C., Ogunfowora, B., Bourdage, J. S., \& Shin, K.-H. (2010). The personality bases of socio-political attitudes: The role of Honesty-Humility and Openness to Experience. Journal of Research in Personality, 44(1), 115-119. https://doi.org/10.1016/j.jrp.2009.08.007

Lee, K., Ashton, M. C., Pozzebon, J. A., Visser, B. A., Bourdage, J. S., \& Ogunfowora, B. (2009). Similarity and assumed similarity in personality reports of well-acquainted 
persons. Journal of Personality and Social Psychology, 96(2), 460-472.

https://doi.org/10.1037/a0014059

Lee, K., Ashton, M. C., Wiltshire, J., Bourdage, J. S., Visser, B. A., \& Gallucci, A. (2013).

Sex, power, and money: Prediction from the Dark Triad and Honesty-Humility. European Journal of Personality, 27(2), 169-184.

Lee, K., Ogunfowora, B., \& Ashton, M. C. (2005). Personality traits beyond the Big Five: Are they within the HEXACO space? Journal of Personality, 73(5), 1437-1463. https://doi.org/10.1111/j.1467-6494.2005.00354.x

Leikas, S., Ilmarinen, V.-J., Verkasalo, M., Vartiainen, H.-L., \& Lönnqvist, J.-E. (2018). Relationship satisfaction and similarity of personality traits, personal values, and attitudes. Personality and Individual Differences, 123(Supplement C), 191-198. https://doi.org/10.1016/j.paid.2017.11.024

Leikas, S., Lönnqvist, J., Verkasalo, M., \& Nissinen, V. (2013). Power and personality perception in real-life hierarchical relationships. European Journal of Personality, 27(2), 155-168. https://doi.org/10.1002/per.1849

Liu, J., Ludeke, S. G., Haubrich, J., Gondan, M., \& Zettler, I. (2018). Similar to and/or better than oneself? Singles' ideal partner personality descriptions. European Journal of Personality. Advance online publication. https://doi.org/10.1002/per.2159

Liu, J., Ludeke, S. G., \& Zettler, I. (n.d.). Assumed similarity in personality within intimate relationships. Personal Relationships.

Locke, K. D., Craig, T., Baik, K.-D., \& Gohil, K. (2012). Binds and bounds of communion: Effects of interpersonal values on assumed similarity of self and others. Journal of Personality and Social Psychology, 103(5), 879-897. https://doi.org/10.1037/a0029422

Luo, S., \& Klohnen, E. C. (2005). Assortative mating and marital quality in newlyweds: A couple-centered approach. Journal of Personality and Social Psychology, 88(2), 304326. https://doi.org/10.1037/0022-3514.88.2.304 
Malloy, T. E., \& Albright, L. (1990). Interpersonal perception in a social context. Journal of Personality and Social Psychology, 58(3), 419-428. https://doi.org/10.1037/00223514.58.3.419

Marcus, B., Lee, K., \& Ashton, M. C. (2007). Personality dimensions explaining relationships between integrity tests and counterproductive behavior: Big five, or one in addition? Personnel Psychology, 60(1), 1-34. https://doi.org/10.1111/j.1744-6570.2007.00063.x

Marks, G., \& Miller, N. (1987). Ten years of research on the false-consensus effect: An empirical and theoretical review. Psychological Bulletin, 102(1), 72-90. https://doi.org/10.1037/0033-2909.102.1.72

Mathison, D. L. (1988). Assumed similarity in communication styles: Implications for personnel interviews. Group \& Organization Studies, 13(1), 100-110. https://doi.org/10.1177/105960118801300111

McCrae, R. R., \& Costa, P. T. (1985). Updating Norman's “adequacy taxonomy”: Intelligence and personality dimensions in natural language and in questionnaires. Journal of Personality and Social Psychology, 49(3), 710-721. https://doi.org/10.1037/0022-3514.49.3.710

McCrae, R. R., Martin, T. A., Hrebícková, M., Urbánek, T., Willemsen, G., \& Costa, P. T. J. (2008). Personality trait similarity between spouses in four cultures. Journal of Personality, 76(5), 1137-1163. https://doi.org/10.1111/j.1467-6494.2008.00517.x

McDade-Montez, E., Watson, D., \& Beer, A. (2013). Similarity, agreement, and assumed similarity in proxy end-of-life decision making. Families, Systems, \& Health, 31(4), 366-381. https://doi.org/10.1037/a0033372

Mollgaard, A., Zettler, I., Dammeyer, J., Jensen, M. H., Lehmann, S., \& Mathiesen, J. (2016). Measure of node similarity in multilayer networks. PLoS ONE, 11(6).

Moshagen, M., Hilbig, B. E., \& Zettler, I. (2014). Faktorstruktur, psychometrische Eigenschaften und Messinvarianz der deutschen Version des 60-Item HEXACO 
Persönlichkeitsinventars [Factor structure, psychometric properties, and measurement invariance of the German-language version of the 60-item HEXACO personality inventory]. Diagnostica, 60(2), 86-97.

Moshagen, M., Zettler, I., \& Hilbig, B. E. (2018). The dark core of personality. Psychological Review. Advance online publication. https://doi.org/10.1037/rev0000111

Murray, S. L., Holmes, J. G., Bellavia, G., Griffin, D. W., \& Dolderman, D. (2002). Kindred spirits? The benefits of egocentrism in close relationships. Journal of Personality and Social Psychology, 82(4), 563-581. https://doi.org/10.1037/0022-3514.82.4.563

Naumann, L. P., Vazire, S., Rentfrow, P. J., \& Gosling, S. D. (2009). Personality judgments based on physical appearance. Personality and Social Psychology Bulletin, 35(12), 1661-1671. https://doi.org/10.1177/0146167209346309

Ott-Holland, C. J., Huang, J. L., Ryan, A. M., Elizondo, F., \& Wadlington, P. L. (2014). The effects of culture and gender on perceived self-other similarity in personality. Journal of Research in Personality, 53, 13-21. https://doi.org/10.1016/j.jrp.2014.07.010

Papp, L. M., Kouros, C. D., \& Cummings, E. M. (2010). Emotions in marital conflict interactions: Empathic accuracy, assumed similarity, and the moderating context of depressive symptoms. Journal of Social and Personal Relationships, 27(3), 367-387. https://doi.org/10.1177/0265407509348810

Paulhus, D. L., \& Reynolds, S. (1995). Enhancing target variance in personality impressions: Highlighting the person in person perception. Journal of Personality and Social Psychology, 69(6), 1233-1242. https://doi.org/10.1037/0022-3514.69.6.1233

Paunonen, S. V. (1989). Consensus in personality judgments: Moderating effects of targetrater acquaintanceship and behavior observability. Journal of Personality and Social Psychology, 56(5), 823-833. https://doi.org/10.1037/0022-3514.56.5.823

Paunonen, S. V, \& Hong, R. Y. (2013). The many faces of assumed similarity in perceptions of personality. Journal of Research in Personality, 47(6), 800-815. 
https://doi.org/10.1016/j.jrp.2013.08.007

Paunonen, S. V, \& Kam, C. (2014). The accuracy of roommate ratings of behaviors versus beliefs. Journal of Research in Personality, 52, 55-67. https://doi.org/10.1016/j.jrp.2014.07.006

Pfattheicher, S., \& Böhm, R. (2018). Honesty-Humility under threat: Self-uncertainty destroys trust among the nice guys. Journal of Personality and Social Psychology, 114(1), 179-194. https://doi.org/10.1037/pspp0000144

Pletzer, J. L., Balliet, D., Joireman, J. A., Kuhlman, D. M., Voelpel, S. C., \& Van Lange, P. A. M. (2018). Social value orientation, expectations, and cooperation in social dilemmas: A meta-analysis. European Journal of Personality, 32(1), 62-83. https://doi.org/10.1002/per.2139

Ready, R. E., Clark, L. A., Watson, D., \& Westerhouse, K. (2000). Self- and peer-related personality: Agreement, trait ratability, and the "self-based heuristic". Journal of Research in Personality, 34(2), 208-224. https://doi.org/10.1006/jrpe.1999.2280

Robbins, J. M., \& Krueger, J. I. (2005). Social projection to ingroups and outgroups: A review and meta-analysis. Personality and Social Psychology Review, 9(1), 32-47. https://doi.org/10.1207/s15327957pspr0901_3

Rogers, K. H., \& Biesanz, J. C. (2014). The accuracy and bias of interpersonal perceptions in intergroup interactions. Social Psychological and Personality Science, 5(8), 918-926. https://doi.org/10.1177/1948550614537307

Ross, L., Greene, D., \& House, P. (1977). The false consensus effect: An egocentric bias in social perception and attribution processes. Journal of Experimental Social Psychology, 13(3), 279-301. https://doi.org/10.1016/0022-1031(77)90049-X

Rushton, J. P., \& Bons, T. A. (2005). Mate choice and friendship in twins: Evidence for genetic similarity. Psychological Science, 16(7), 555-559. https://doi.org/10.1111/j.0956-7976.2005.01574.x 
Schwartz, S. H. (1992). Universals in the content and structure of values: Theoretical advances and empirical tests in 20 countries. In M. P. Zanna (Ed.), Advances in experimental social psychology, Vol. 25. (pp. 1-65). Academic Press. https://doi.org/10.1016/S0065-2601(08)60281-6

Schwartz, S. H., Cieciuch, J., Vecchione, M., Davidov, E., Fischer, R., Beierlein, C., ... Konty, M. (2012). Refining the theory of basic individual values. Journal of Personality and Social Psychology, 103(4), 663-688. https://doi.org/10.1037/a0029393

Selfhout, M., Denissen, J. J. A., Branje, S., \& Meeus, W. (2009). In the eye of the beholder: Perceived, actual, and peer-rated similarity in personality, communication, and friendship intensity during the acquaintanceship process. Journal of Personality and Social Psychology, 96(6), 1152-1165. https://doi.org/10.1037/a0014468

Sherwood, G. G. (1981). Self-serving biases in person perception: A reexamination of projection as a mechanism of defense. Psychological Bulletin, 90(3), 445-459. https://doi.org/10.1037/0033-2909.90.3.445

Spearman, C. (1904). The proof and measurement of association between two things. The American Journal of Psychology, 15(1), 72-101. https://doi.org/10.2307/1412159

Srivastava, S., Guglielmo, S., \& Beer, J. S. (2010). Perceiving others' personalities: examining the dimensionality, assumed similarity to the self, and stability of perceiver effects. Journal of Personality and Social Psychology, 98(3), 520-534. https://doi.org/10.1037/a0017057

Thielmann, I., \& Hilbig, B. E. (2015). The traits one can trust: Dissecting reciprocity and kindness as determinants of trustworthy behavior. Personality and Social Psychology Bulletin, 41(11), 1523-1536. https://doi.org/10.1177/0146167215600530

Thielmann, I., \& Hilbig, B. E. (2018). Is it all about the money? A re-analysis of the link between Honesty-Humility and Dictator Game giving. Journal of Research in Personality, 76, 1-5. https://doi.org/10.1016/j.jrp.2018.07.002 
Thielmann, I., Zimmermann, J., Leising, D., \& Hilbig, B. E. (2017). Seeing is knowing: On the predictive accuracy of self- and informant reports for prosocial and moral behaviours. European Journal of Personality, 31(4), 404-418. https://doi.org/10.1002/per.2112

Vazire, S. (2010). Who knows what about a person? The self-other knowledge asymmetry (SOKA) model. Journal of Personality and Social Psychology, 98(2), 281-300. https://doi.org/10.1037/a0017908

Vazire, S., Naumann, L. P., Rentfrow, P. J., \& Gosling, S. D. (2008). Portrait of a narcissist: Manifestations of narcissism in physical appearance. Journal of Research in Personality, 42(6), 1439-1447.

Watson, D., \& Clark, L. A. (1994). Manual for the Positive and Negative Affect Schedule (expanded fom). Iowa City, IA, US.

Watson, D., Clark, L. A., \& Tellegen, A. (1988). Development and validation of brief measures of positive and negative affect: the PANAS scales. Journal of Personality and Social Psychology, 54(6), 1063-1070.

Watson, D., Hubbard, B., \& Wiese, D. (2000). Self-other agreement in personality and affectivity: The role of acquaintanceship, trait visibility, and assumed similarity. Journal of Personality and Social Psychology, 78(3), 546-558. https://doi.org/10.1037/00223514.78.3.546

Watson, D., Klohnen, E. C., Casillas, A., Nus Simms, E., Haig, J., \& Berry, D. S. (2004). Match makers and deal breakers: Analyses of assortative mating in newlywed couples. Journal of Personality, 72(5), 1029-1068. https://doi.org/10.1111/j.00223506.2004.00289.x

Weller, J., \& Watson, D. (2009). Friend or foe? Differential use of the self-based heuristic as a function of relationship satisfaction. Journal of Personality, 77(3), 731-760. https://doi.org/10.1111/j.1467-6494.2009.00563.x

Wood, D., Harms, P., \& Vazire, S. (2010). Perceiver effects as projective tests: what your 
perceptions of others say about you. Journal of Personality and Social Psychology, 99(1), 174-190. https://doi.org/10.1037/a0019390

Youyou, W., Stillwell, D., Schwartz, H. A., \& Kosinski, M. (2017). Birds of a feather do flock together: Behavior-based personality-assessment method reveals personality similarity among couples and friends. Psychological Science, 28(3), 276-284. https://doi.org/10.1177/0956797616678187

Zhang, X., Xing, C., Guan, Y., Song, X., Melloy, R., Wang, F., \& Jin, X. (2016). Attitudes toward older adults: A matter of cultural values or personal values? Psychology and Aging, 31(1), 89-100. https://doi.org/10.1037/pag0000068

Zhao, K., \& Smillie, L. D. (2015). The role of interpersonal traits in social decision making: Exploring sources of behavioral heterogeneity in economic games. Personality and Social Psychology Review, 19(3), 277-302. https://doi.org/10.1177/1088868314553709 
Tables

Table 1

Summary of studies on assumed similarity in personality judgments of basic personality traits (Five-Factor Model and HEXACO Model), with sample size-weighted meta-analytic correlations.

\begin{tabular}{|c|c|c|c|c|c|c|c|}
\hline \multirow{2}{*}{$\begin{array}{l}\text { Reference } \\
\text { Five-Factor Model }\end{array}$} & \multirow[t]{2}{*}{$N$} & \multirow[t]{2}{*}{ Relationship } & \multicolumn{5}{|c|}{ Assumed similarity correlations } \\
\hline & & & & & & & \\
\hline & & & $\mathrm{Ne}$ & $\mathrm{X}$ & A & $\mathrm{C}$ & $\mathrm{O}$ \\
\hline Beer \& Watson (2008) & 215 & unacquainted & .32 & -.07 & .38 & .25 & .07 \\
\hline Beer, Watson, \& McDade-Montez (2013) & 381 & newlyweds & -.08 & .01 & .15 & -.03 & .38 \\
\hline $\begin{array}{l}\text { Cohen, Panter, Turan, Morse, \& Kim (2013), } \\
\text { Study } 1\end{array}$ & 320 & $\begin{array}{l}\text { well-acquainted (friends, spouses, } \\
\text { relatives, etc.) }\end{array}$ & .06 & -.02 & .15 & .10 & .07 \\
\hline $\begin{array}{l}\text { Leikas, Lönnqvist, Verkasalo, \& Nissinen } \\
(2013)^{\mathrm{a}}\end{array}$ & 37 & co-workers & .30 & .12 & .43 & .25 & .31 \\
\hline $\begin{array}{l}\text { McCrae, Martin, Hrebícková, Urbánek, } \\
\text { Willemsen, \& Costa (2008), US sample }\end{array}$ & 394 & spouses & .12 & .09 & .18 & .15 & .21 \\
\hline $\begin{array}{l}\text { McCrae, Martin, Hrebícková, Urbánek, } \\
\text { Willemsen, \& Costa (2008), Czech sample }\end{array}$ & 264 & spouses & .07 & .00 & .27 & -.06 & .21 \\
\hline Paulhus \& Reynolds (1995), Study $1^{\mathrm{c}, \mathrm{d}, \mathrm{e}}$ & 79 & $\begin{array}{l}\text { unacquainted at first rating; second } \\
\text { rating after weekly discussion } \\
\text { sessions across } 7 \text { weeks }\end{array}$ & -.43 & -.02 & .41 & .29 & .12 \\
\hline
\end{tabular}


Paulhus \& Reynolds (1995), Study $2^{\text {c,d,e }}$

Paulhus \& Reynolds (1995), Study $3^{\text {c,d,e }}$

Paunonen \& Hong (2013)

Srivastava, Guglielmo, \& Beer (2010), Study

$1^{\mathrm{d}}$

Srivastava, Guglielmo, \& Beer (2010), Study $2^{\mathrm{c}, \mathrm{d}}$

Watson, Hubbard, \& Wiese (2000) ${ }^{\mathrm{c}}$

Weller \& Watson (2009), Study $1^{\text {c }}$

Weller \& Watson (2009), Study $2^{c}$

Wood, Harms, \& Vazire (2010), Study 1

Wood, Harms, \& Vazire (2010), Study 2

Wood, Harms, \& Vazire (2010), Study 3 unacquainted at first rating; second

sessions across 7 weeks

59 unacquainted at first rating; second

rating after weekly discussion

sessions across 7 weeks

roommates

initially unacquainted, rating after group game

initially unacquainted; rating after group task at 4 measurement

occasions

978 well-acquainted (married couples, dating couples, and friends)

440 friend, foe

260 friend, foe

165 friends

364 dormitory floor mates

311 organization members rating after weekly discussion

$\begin{array}{llll}.23 & .14 & .61 & .18\end{array}$

$\begin{array}{llll}15 & .30 & .46 & .27\end{array}$

$\begin{array}{lllll}.37 & .25 & .34 & .23 & .44\end{array}$

$\begin{array}{lllll}.29 & .20 & .45 & .18 & .25\end{array}$

$\begin{array}{lllll}.15 & .36 & .22 & .23 & .20\end{array}$

5,024

$\begin{array}{lllll}.16 & .15 & .24 & .14 & .30 \\ .06 & .12 & .12 & .12 & .27 \\ .02 & .04 & .18 & .14 & .20 \\ .14 & -.04 & .19 & .09 & .16 \\ .15 & .04 & .29 & .19 & .17 \\ .21 & .07 & .24 & .11 & .19 \\ . \mathbf{1 3} & \mathbf{. 0 9} & . \mathbf{2 5} & \mathbf{. 1 3} & \mathbf{. 2 3}\end{array}$




\section{HEXACO Model}
2,134 well-acquainted (friends, romantic partners)

Cohen, Panter, Turan, Morse, \& Kim (2013), 320

Study 1

Cohen, Panter, Turan, Morse, \& Kim (2013), 341 Study 2

De Vries (2010)

Liu, Ludeke, \& Zettler (in press), Study 1

Liu, Ludeke, \& Zettler (in press), Study 2

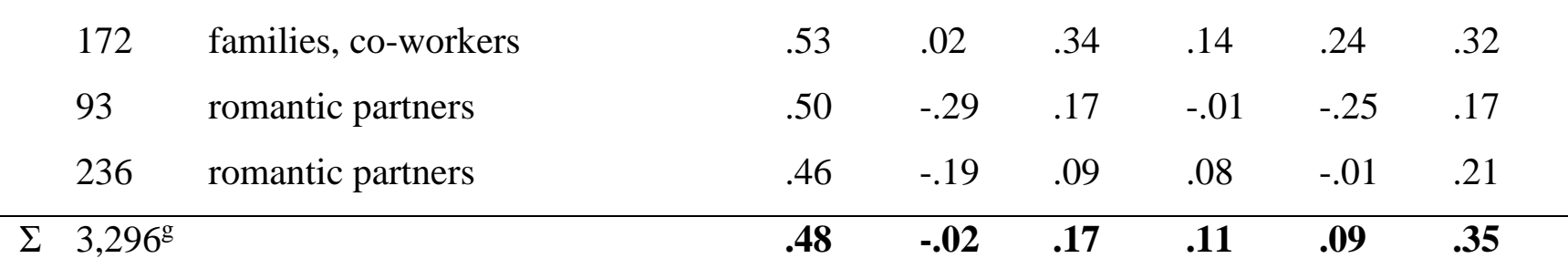

Note. $\mathrm{A}=$ Agreeableness, $\mathrm{C}=$ Conscientiousness, $\mathrm{E}=$ Emotionality, $\mathrm{H}=$ Honesty-Humility, $\mathrm{Ne}=$ Neuroticism, $\mathrm{O}=\mathrm{Openness}, \mathrm{X}=\mathrm{Extraversion}$. Note that two HEXACO dimensions - Emotionality and Agreeableness - reflect rotated variants of their FFM counterparts (Ashton \& Lee, 2007; Ashton et al., 2014), which is why these dimensions capture slightly different content across the two personality models.

${ }^{\text {a }}$ Effect sizes correspond to standardized regression coefficients.

${ }^{\mathrm{b}}$ Upon personal communication with R. R. McCrae, we omitted inclusion of their Russian sample given that several participants seem to have mistakenly provided a self-report instead of an observer report of their spouses, thus artificially increasing corresponding assumed similarity correlations.

${ }^{\mathrm{c}}$ Correlations correspond to sample size-weighted average values aggregated across multiple measurement occasions or groups.

${ }^{\mathrm{d}}$ Correlations are based on perceiver effects from Social Relations Model (SRM) analysis.

${ }^{\mathrm{e}}$ Correlations are disattenuated.

${ }^{\mathrm{f}}$ The data reported in Ashton, Lee, and De Vries (2014) contain the data reported by Lee and colleagues (2009).

$\mathrm{g}$ The total sample size for all dimensions but Honesty-Humility was slightly lower (i.e., $N=2,976$ ). 
Table 2

Assumed similarity and actual similarity correlations for the three raters (Study 1). Correlations in parentheses denote partial correlations between self- and observer reports controlled for targets' self-reports.

\begin{tabular}{|c|c|c|c|c|c|c|}
\hline & \multicolumn{3}{|c|}{ Assumed similarity } & \multicolumn{3}{|c|}{ Actual similarity } \\
\hline & Roommate & Fellow student & Stranger & Roommate & Fellow student & Stranger \\
\hline Honesty-Humility & $.34 * *(.27 *)$ & $.54 * * *\left(.55^{* * *}\right)$ & $.43 * * *(.43 * * *)$ & $.29 *$ & .10 & .08 \\
\hline Emotionality & $-.05(.03)$ & $.12\left(.22^{\dagger}\right)$ & $.06(.06)$ & -.10 & -.21 & .02 \\
\hline Extraversion & $-.06(-.02)$ & $.37 * *(.33 * *)$ & $-.09(-.09)$ & -.08 & $.24^{\dagger}$ & -.02 \\
\hline Agreeableness & $.07\left(.22^{\dagger}\right)$ & $-.02(.09)$ & $.08(.08)$ & -.15 & -.19 & .07 \\
\hline Conscientiousness & $-.03(-.27)$ & $.07(-.08)$ & $-.05(-.05)$ & $.31 *$ & $.30 *$ & .08 \\
\hline Openness to Experience & $.38 * *\left(.40^{* *}\right)$ & $.34 * *(.30 *)$ & $.21(.24 *)$ & .08 & .19 & .16 \\
\hline
\end{tabular}

Note. $N=57$ for fellow students and strangers, $N=56$ for roommates.

$* * * p<.001, * * p<.01, * p<.05,{ }^{\dagger} p<.10$. All (positive) assumed similarity correlations are tested one-tailed. 
Table 3

Assumed similarity and actual similarity correlations (Study 2). Correlations in parentheses denote partial correlations between self- and observer reports controlled for targets' selfreports.

\begin{tabular}{lcc}
\hline & Assumed similarity & Actual similarity \\
\hline Honesty-Humility & $.21 *\left(.21^{*}\right)$ & -.09 \\
Emotionality & $.03(.01)$ & .07 \\
Extraversion & $-.10(-.11)$ & .13 \\
Agreeableness & $.00(.00)$ & .05 \\
Conscientiousness & $-.10(-.08)$ & -.10 \\
Openness to Experience & $.09(.10)$ & $-.30 *$
\end{tabular}

Note. $N=70$.

$* p<.05$. All (positive) assumed similarity correlations are tested one-tailed. 
Table 4

Assumed similarity and actual similarity correlations (Study 3). Correlations in parentheses denote partial correlations between self- and observer reports controlled for targets' selfreports.

\begin{tabular}{lcc}
\hline & Assumed similarity & Actual similarity \\
\hline Honesty-Humility & $.26^{*}\left(.26^{*}\right)$ & .04 \\
Emotionality & $-.11(-.11)$ & -.01 \\
Extraversion & $-.01(.00)$ & .06 \\
Agreeableness & $.06(.06)$ & $.28^{*}$ \\
Conscientiousness & $-.21(-.21)$ & .15 \\
Openness to Experience & $.13(.12)$ & .14
\end{tabular}

Note. $N=81$.

$* p<.05$. All (positive) assumed similarity correlations are tested one-tailed. 
Table 5

Assumed similarity correlations for HEXACO facets (Study 3).

\begin{tabular}{|c|c|}
\hline HEXACO facet & Assumed similarity \\
\hline HH sincerity & .14 \\
\hline HH fairness & $.46 * * *$ \\
\hline HH greed-avoidance & $.26 * *$ \\
\hline HH modesty & $.18^{\dagger}$ \\
\hline EM fearfulness & -.15 \\
\hline EM anxiety & -.10 \\
\hline EM dependence & .01 \\
\hline EM sentimentality & -.12 \\
\hline EX social self-esteem & .08 \\
\hline EX social boldness & -.13 \\
\hline EX sociability & -.10 \\
\hline EX liveliness & .12 \\
\hline AG forgivingness & .14 \\
\hline AG gentleness & -.02 \\
\hline AG flexibility & .11 \\
\hline AG patience & .03 \\
\hline $\mathrm{CO}$ organization & -.19 \\
\hline $\mathrm{CO}$ diligence & -.15 \\
\hline $\mathrm{CO}$ perfectionism & -.18 \\
\hline $\mathrm{CO}$ prudence & -.01 \\
\hline OP aesthetic appreciation & $.25^{*}$ \\
\hline OP inquisitiveness & $.18^{*}$ \\
\hline OP creativity & -.13 \\
\hline OP unconventionality & .02 \\
\hline
\end{tabular}

Note. $N=81 ; \mathrm{HH}=$ Honesty-Humility; $\mathrm{EM}=$ Emotionality; $\mathrm{EX}=$ Extraversion; $\mathrm{AG}=$ Agreeableness; $\mathrm{CO}=$ Conscientiousness; $\mathrm{OP}=$ Openness to Experience .

$* * * p<.001, * * p<.01, * p<.05,{ }^{\dagger} p<.10$. All (positive) assumed similarity correlations are tested one-tailed. 
Table 6

Assumed similarity and actual similarity correlations for same sex and opposite sex targets (Study 4). Correlations in parentheses denote partial correlations between self- and observer reports controlled for targets' self-reports.

\begin{tabular}{lccccc}
\hline & \multicolumn{2}{c}{ Assumed similarity } & & \multicolumn{2}{c}{ Actual similarity } \\
\cline { 2 - 3 } \cline { 5 - 6 } & Same sex & Opposite sex & & Same sex & Opposite sex \\
\hline Honesty-Humility & $.30^{* *}\left(.31^{* *}\right)$ & $.18^{*}\left(.18^{*}\right)$ & & .00 & .06 \\
Emotionality & $.41^{* * *}\left(.37^{* * *}\right)$ &.$- .46(-.39)$ & & $.28^{* *}$ & $-.35^{* * *}$ \\
Extraversion & $.13(.15)$ & $-.07(-.07)$ & & -.08 & .00 \\
Agreeableness & $-.13(-.12)$ & $.14^{\dagger}(.15)$ & & .08 & -.04 \\
Conscientiousness & $.15^{\dagger}(.15)$ & $-.17(-.17)$ & & -.02 & -.04 \\
Openness to Experience & $.08(.10)$ & $.05(.08)$ & & -.10 & -.13 \\
\hline
\end{tabular}

Note. $N=95$.

$* * * p<.001, * * p<.01, * p<.05,{ }^{\dagger} p<.10$. All (positive) assumed similarity correlations are tested one-tailed. 
Table 7

Assumed similarity with typical psychology student and typical young adult (Study 5).

\begin{tabular}{lcc}
\hline & Psychology student & Young adult \\
\hline Honesty-Humility & $.31^{* * *}$ & $.36^{* * *}$ \\
Emotionality & $.16^{*}$ & -.09 \\
Extraversion & -.13 & -.21 \\
Agreeableness & $.24 * *$ & -.05 \\
Conscientiousness & .08 & -.14 \\
Openness to Experience & $.18^{*}$ & $.29 * * *$ \\
\hline
\end{tabular}

Note. $N=122$.

$* * * p<.001, * * p<.01, * p<.05$. All (positive) assumed similarity correlations are tested one-tailed. 
Table 8

Descriptive statistics of self-relevance rating of HEXACO dimensions, with corresponding $t$ test statistics for the comparison of each dimensions to Honesty-Humility and Openness to Experience (Study 6).

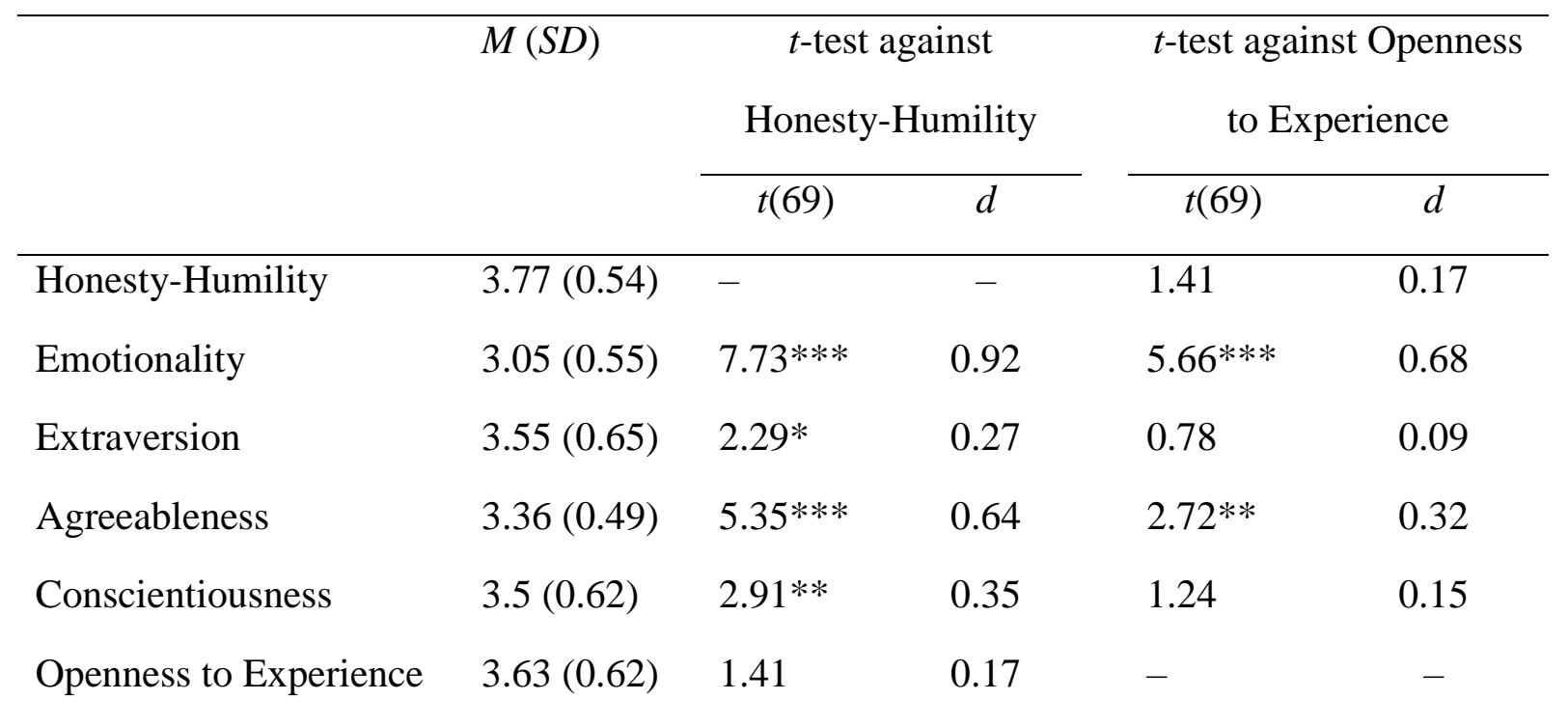

Note. $N=70$.

$* * * p<.001, * * p<.01, * p<.05$. 
Table 9

Mean assumed similarity and actual similarity correlations across targets in no-priming and priming condition (Study 7). Correlations in parentheses denote partial correlations between self- and observer reports controlled for targets'self-reports.

\begin{tabular}{lccccc}
\hline & \multicolumn{2}{c}{ Assumed similarity } & & \multicolumn{2}{c}{ Actual similarity } \\
\cline { 2 - 3 } \cline { 5 - 6 } & No priming & Priming & & No priming & Priming \\
\hline Honesty-Humility & $.14(.14)$ & $.52^{* * *}\left(.51^{* * *}\right)$ & & -.01 & .12 \\
Emotionality & $-.03(-.03)$ & $.13(.17)$ & & -.02 & $-.26^{\dagger}$ \\
Extraversion & $.05(.06)$ & $.01(.00)$ & & -.03 & .22 \\
Agreeableness & $.07(.08)$ & $.38^{* *}\left(.36^{* *}\right)$ & & -.13 & -.22 \\
Conscientiousness & $.15(.14)$ & $.02(.07)$ & & -.08 & .14 \\
Openness to Experience & $.18(.15)$ & $.05(.05)$ & & $.26^{\dagger}$ & .07 \\
\hline
\end{tabular}

Note. $N=49$ per condition.

$* * * p<.001, * * p<.01,{ }^{\dagger} p<.10$. All (positive) assumed similarity correlations are tested one-tailed. 
Table 10

Mean assumed similarity and actual similarity correlations across targets (Study 8).

Correlations in parentheses denote partial correlations between self- and observer reports controlled for targets' self-reports.

\begin{tabular}{lcc}
\hline & Assumed similarity & Actual similarity \\
\hline Honesty-Humility & $.31^{* * *}\left(.31^{* * *}\right)$ & .00 \\
Emotionality & $.25^{* *}\left(.25^{* *}\right)$ & -.02 \\
Extraversion & $-.06(-.06)$ & .05 \\
Agreeableness & $-.05(-.06)$ & -.09 \\
Conscientiousness & $.11(.11)$ & .01 \\
Openness to Experience & $-.03(-.03)$ & -.02
\end{tabular}

Note. $N=109$.

$* * * p<.001, * * p<.01$. All (positive) assumed similarity correlations are tested one-tailed. 
Table 11

Means, standard deviations (in parentheses), internal consistencies (Cronbach's $\alpha$ ), and correlations of personal relevance ratings (Study 8).

\begin{tabular}{llllllll}
\hline Dimension & $M(S D)$ & \multicolumn{6}{c}{ Correlations } \\
\cline { 3 - 8 } & & 1 & 2 & 3 & 4 & 5 & 6 \\
\hline 1. Honesty-Humility & $3.81(0.85)$ & .80 & & & & \\
2. Emotionality & $3.55(0.56)$ & .17 & .50 & & & & \\
3. Extraversion & $3.64(0.80)$ & $.48^{* * *}$ & $.44^{* * *}$ & .81 & & & \\
4. Agreeableness & $3.43(0.72)$ & $.70^{* * *}$ & $.42^{* * *}$ & $.48^{* * *}$ & .74 & & \\
5. Conscientiousness & $3.49(0.71)$ & $.54^{* * *}$ & $.21^{*}$ & $.37^{* * *}$ & $.49^{* * *}$ & .77 & \\
6. Openness & $3.49(0.70)$ & $.51^{* * *}$ & $.34^{* * *}$ & $.40^{* * *}$ & $.45^{* * * *}$ & $.51 * * *$ & .61 \\
\hline
\end{tabular}

Note. $N=109$.

$* * * p<.001, * p<.05$. 
Table 12

Assumed similarity correlations across priming conditions as well as separated for otherpriming and priming conditions (Study 9).

\begin{tabular}{lccc}
\hline & Overall & Not primed & Primed \\
\hline Honesty-Humility & $.28^{* * *}$ & $.28 * * *$ & $.28^{* *}$ \\
Emotionality & $.08^{*}$ & $.08^{*}$ & .12 \\
Extraversion & $.12 * *$ & $.09 *$ & $.24 * *$ \\
Agreeableness & $.27 * * *$ & $.29 * * *$ & $.17 *$ \\
Conscientiousness & $.12 * *$ & $.11^{* *}$ & .14 \\
Openness to Experience & $.17 * * *$ & $.13^{* *}$ & $.32 * * *$ \\
\hline
\end{tabular}

Note. $N=604$ across conditions (overall); $497 \leq N \leq 512$ in "not primed" condition and $92 \leq$ $N \leq 107$ in "primed" condition.

$* * * p<.001, * * p<.01, * p<.05$. All (positive) assumed similarity correlations are tested one-tailed. 


\section{Figures}
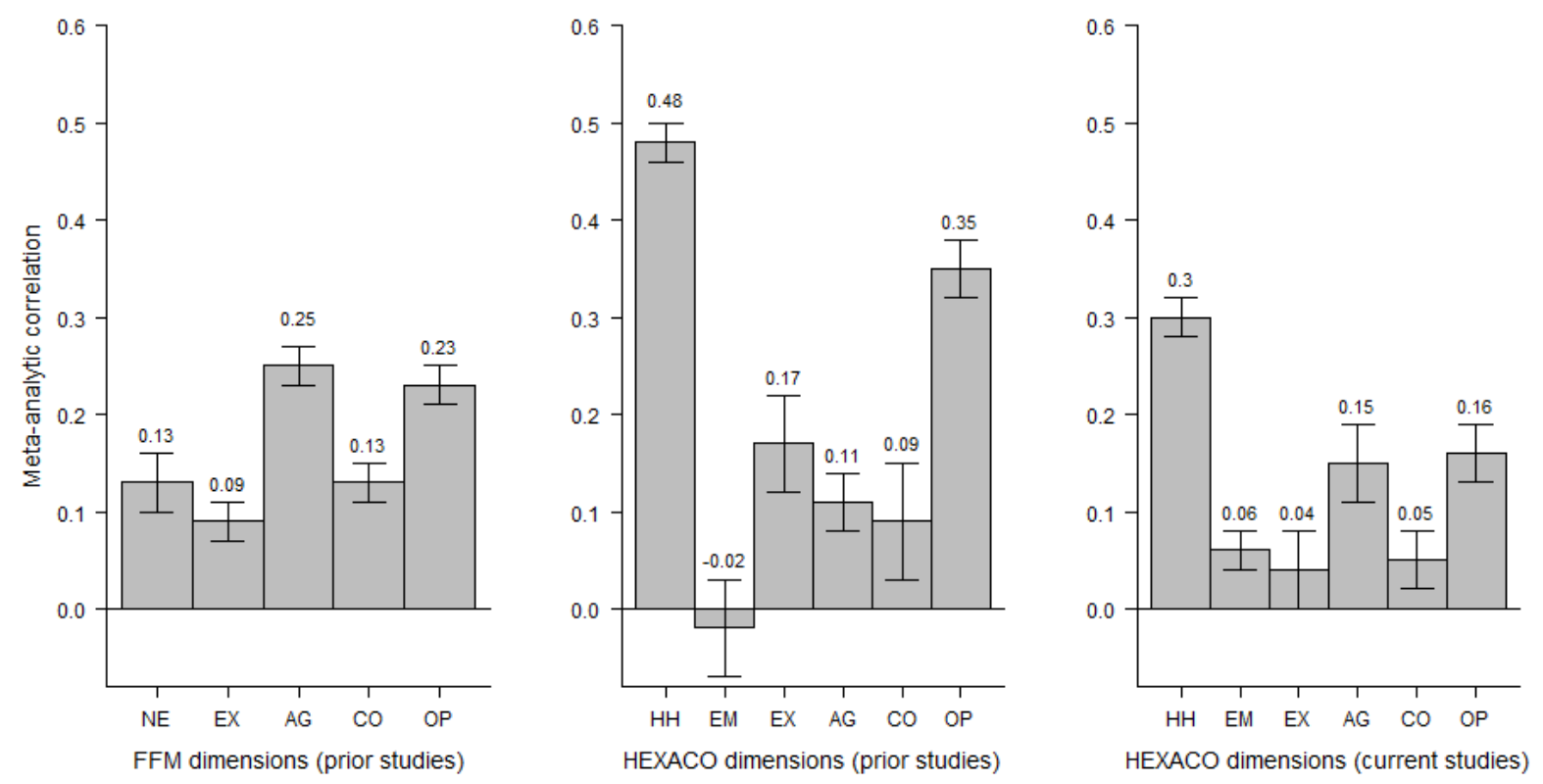

Figure 1. Meta-analytic assumed similarity correlations $(\bar{r})$ for the FFM dimensions (prior studies; left panel) and the HEXACO dimensions (prior studies based on acquainted others and current studies mostly based on strangers; middle and right panel, respectively). Errors bars represent one standard error. 